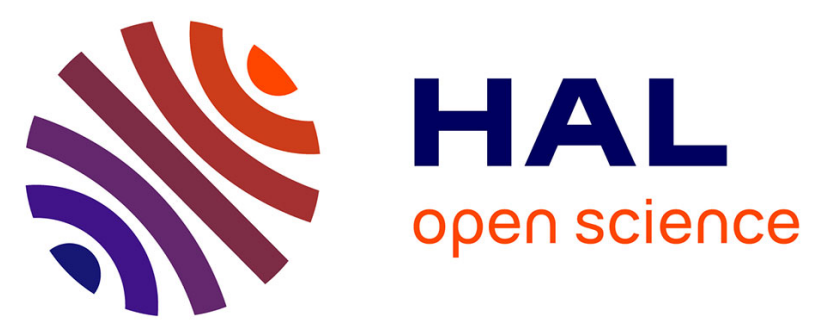

\title{
Cation Engineering in Two-Dimensional Ruddlesden-Popper Lead Iodide Perovskites with Mixed Large A-Site Cations in the Cages
}

Yongping Fu, Xinyi Jiang, Xiaotong Li, Boubacar Traore, Ioannis Spanopoulos, Claudine Katan, Jacky Even, Mercouri G Kanatzidis, Elad Harel

\section{To cite this version:}

Yongping Fu, Xinyi Jiang, Xiaotong Li, Boubacar Traore, Ioannis Spanopoulos, et al.. Cation Engineering in Two-Dimensional Ruddlesden-Popper Lead Iodide Perovskites with Mixed Large A-Site Cations in the Cages. Journal of the American Chemical Society, 2020, 142 (8), pp.4008-4021. 10.1021/jacs.9b13587 . hal-02471818

\author{
HAL Id: hal-02471818 \\ https://hal.science/hal-02471818
}

Submitted on 25 Mar 2020

HAL is a multi-disciplinary open access archive for the deposit and dissemination of scientific research documents, whether they are published or not. The documents may come from teaching and research institutions in France or abroad, or from public or private research centers.
L'archive ouverte pluridisciplinaire HAL, est destinée au dépôt et à la diffusion de documents scientifiques de niveau recherche, publiés ou non, émanant des établissements d'enseignement et de recherche français ou étrangers, des laboratoires publics ou privés. 


\title{
Cation Engineering in Two-Dimensional Ruddlesden-Popper Lead
}

\section{Iodide Perovskites with Mixed Large A-Site Cations in the Cages}

Yongping $\mathrm{Fu}^{\dagger}{ }^{1}$, Xinyi Jiang ${ }^{\dagger}{ }^{1}$, Xiaotong $\mathrm{Li}^{\dagger}$, Boubacar Traore ${ }^{\#}$, Ioannis Spanopoulos ${ }^{\dagger}$, Claudine

Katan $^{\#}$, Jacky Even $^{\S}$, Mercouri G. Kanatzidis', Elad Harel'广**

$\dagger^{\dagger}$ Department of Chemistry, Northwestern University, Evanston, Illinois 60208, United States

${ }^{\dagger}$ Department of Chemistry, Michigan State University, East Lansing, Michigan 48824, United

States

\# Univ Rennes, ENSCR, INSA Rennes, CNRS, ISCR (Institut des Sciences Chimiques de Rennes) UMR 6226, 35000 Rennes, France

§ Univ Rennes, INSA Rennes, CNRS, Institut FOTON - UMR 6082, 35000 Rennes, France

* Corresponding author: E-mail: elharel@msu.edu

${ }^{1}$ These authors contributed equally to this work.

\begin{abstract}
The Goldschmidt tolerance factor in halide perovskites limits the number of cations that can enter their cages without destabilizing their overall structure. Here we have explored the limits of this geometric factor and found that the ethylammonium (EA) cations which lie outside the tolerance factor range can still enter the cages of the 2D halide perovskites by stretching them. The new perovskites allow us to study how these large cations occupying the perovskite cages affect
\end{abstract}


the structural, optical, and electronic properties. We report a series of cation engineered 2D Ruddlesden-Popper lead iodide perovskites $(\mathrm{BA})_{2}\left(\mathrm{EA}_{x} \mathrm{MA}_{1-x}\right)_{2} \mathrm{~Pb}_{3} \mathrm{I}_{10} \quad(x=0-1$, $\mathrm{BA}$ is $n$ butylammonium, MA is methylammonium) by incorporating large EA cation in the cage. Analysis of the single-crystal structures reveals that the incorporation of EA in the cage significantly stretches $\mathrm{Pb}-\mathrm{I}$ bonds, expands the cage, and induces a large octahedral distortion in the inorganic framework. Spectroscopic and theoretical studies show that such structural deformation leads to a blue-shifted bandgap, sub-bandgap trap states with wider energetic distribution, and stronger photoluminescence quenching. These results enrich the family of $2 \mathrm{D}$ perovskites and provide new insights for understanding the structure-property relationship in perovskite materials.

\section{INTRODUCTION}

Lead halide perovskites have revolutionized the fields of photovoltaics and optoelectronics as promising semiconductors. ${ }^{1-4}$ Since the first incorporation of $\mathrm{CsSnI}_{3}$ and $\mathrm{CH}_{3} \mathrm{NH}_{3} \mathrm{PbI}_{3}$ in solar cells ${ }^{3,4}$, high performance photovoltaic and optoelectronic devices have been achieved with this class of materials adopting a three-dimensional (3D) perovskite structure of $\mathrm{APbX}_{3}$, where $\mathrm{A}$ is $\mathrm{Cs}^{+}, \mathrm{CH}_{3} \mathrm{NH}_{3}{ }^{+}(\mathrm{MA})$, or $\left[\mathrm{HC}\left(\mathrm{NH}_{2}\right)_{2}\right]^{+}(\mathrm{FA})$, and $\mathrm{X}$ is a halide anion. The crystal structure consists of $3 \mathrm{D}$ corner sharing $\mathrm{PbX}_{6}^{4-}$ octahedra with the A cation occupying the cuboctahedral site formed in the middle of eight adjacent octahedra. Recently, the two-dimensional (2D) perovskite derivatives have been demonstrated as promising more stable alternatives to their $3 \mathrm{D}$ counterparts for solar cells and light emitting diodes. ${ }^{5}$ It is not only the increased chemical stability but also the more diverse and tunable optical and electronic properties that make this class of perovskites highly attractive for investigation. ${ }^{6-11}$ The family of $2 \mathrm{D}$ perovskites has a general formula of $\left(\mathrm{A}^{\prime}\right)_{m}(\mathrm{~A})_{n-1} \mathrm{~Pb}_{n} \mathrm{X}_{3 n+1}$, where $\mathrm{A}^{\prime}$ is a large monovalent $(m=2)$ or divalent $(m=1)$ organic cation, 
and $n$ is an integer that indicates the thickness of the perovskite layer. Conceptually these materials derive by slicing the 3D perovskites structure along the (100) plane and incorporating large spacer cations ( $\mathrm{A}^{\prime}$ ) between the resulting layers. Most of reported 2D structures can be considered as selfassembled multiple quantum wells with charge carriers confined in the perovskite layers due to both the wider bandgap and the lower dielectric constant of the organic spacer.6,12-14

With a view to further enhancing device efficiency, extensive studies have been carried out to understand the role played by the A-cations in structural, optoelectronic, and charge carrier properties. The desirable photophysical properties have been mostly attributed to the inorganic framework because, in most known compounds, the A-cation does not directly contribute to the electronic structure of band edge states, but it does so indirectly. ${ }^{15}$ Comparative studies on the three $\mathrm{APbBr}_{3}(\mathrm{~A}=\mathrm{Cs}, \mathrm{MA}$ or $\mathrm{FA})$ perovskites showing markedly similar carrier properties and device performance further support such a picture. Nevertheless, the interplay between the A cation and the inorganic framework may influence the optoelectronic properties and carrier dynamics. For example, the bandgap of $3 \mathrm{D} \mathrm{APbI}_{3}$ decreases with increasing size of A-cation due to the decrease of octahedral tilt which is characterized by the $\mathrm{Pb}-\mathrm{I}-\mathrm{Pb}$ angle. ${ }^{16,17}$ Moreover, there have been several proposals as how A-site cations may contribute to the remarkable carrier properties such as long-lived carriers and long carrier diffusion lengths. ${ }^{18-21}$ These mechanistic studies suggested unusual structure-property relationships such as formation of ferroelectric domains, local symmetry breaking, large polaron formation, and dynamic Rashba effect that might be closely associated with the dynamic disorder and polarity of the A-site cations. ${ }^{22-26}$ Despite progress in our understanding, further investigation on the structure-property relationship is hindered by the limited options of A-cations in 3D perovskites due to the geometric consideration of the so-called Goldschmidt rule. ${ }^{27-29}$ In general, the formation of a perovskite structure depends 
on Goldschmidt tolerance factor $(t), t=\left(r_{A}+r_{X}\right) /\left[\sqrt{2}\left(r_{P b}+r_{X}\right)\right]$, in which $r_{A}, r_{P b}$, and $r_{X}$ is the effective radii of $\mathrm{A}, \mathrm{Pb}$, and $\mathrm{X}$ ion. Large (such as $\mathrm{EA}$ ) or small (such as $\mathrm{Rb}$ ) cations can result in non-perovskite structures due to the large ionic size mismatches (i.e. $t>1$ or $t<0.8$ ).

In this article, we advance fundamental understanding on the structure-property relationship in lead iodide perovskites by studying new 2D crystal structures with unusual A-cations which do not follow the Goldschmidt rule and use these materials to perform ultrafast spectroscopic studies. Large organic cations such as guanidinium, dimethylammonium, and ethylammonium cannot by themselves crystallize in a $3 \mathrm{D}$ perovskite structure but can be alloyed into the $3 \mathrm{D}$ lattice of $\mathrm{MAPbI}_{3}$ or $\mathrm{CsPbI}_{3}$ to form mixed-cation compositions which is referred to as tuning of the effective Goldschmidt tolerance factor. ${ }^{30-32}$ Some other large cations such as ethylenediammonium can be incorporated into a 3D perovskite structure with expelling metal and halide atoms from the structure, forming a discontinuous perovskite lattice. ${ }^{33-35}$ While chemical engineering of 2D perovskites has focused in the past on changing the organic cation occupying the $\mathrm{A}^{\prime}$-site ${ }^{9,36}$, recent studies pointed out that the Goldschmidt rule could be relaxed in the $2 \mathrm{D}$ perovskites, ${ }^{37}$ allowing large organic cations to occupy the perovskite cages (A-site). This was unambiguously demonstrated by a few crystallographically well characterized $2 \mathrm{D}$ perovskites including $(n$ $\left.\mathrm{C}_{6} \mathrm{H}_{13} \mathrm{NH}_{3}\right)_{2}\left[\mathrm{C}\left(\mathrm{NH}_{2}\right)_{3}\right] \mathrm{Pb}_{2} \mathrm{I}_{7},{ }^{37} \quad\left(n-\mathrm{C}_{5} \mathrm{H}_{11} \mathrm{NH}_{3}\right)_{2}\left[\mathrm{C}\left(\mathrm{NH}_{2}\right)_{3}\right] \mathrm{Pb}_{2} \mathrm{I}_{7},{ }^{38} \quad(i-\mathrm{PA})_{2}(i-\mathrm{PA}) \mathrm{Sn}_{2} \mathrm{I}_{7} \quad[i-\mathrm{PA}=$ $\left.\left(\mathrm{CH}_{3}\right)_{2} \mathrm{CHNH}_{3}{ }^{+}\right],{ }^{15}$ and $(\mathrm{EA})_{2}(\mathrm{EA})_{2} \mathrm{~Pb}_{3} \mathrm{X}_{10}(\mathrm{X}=\mathrm{Cl}, \mathrm{Br}) .{ }^{39-41}$ The relaxed Goldschmidt rule significantly expands the library of 2D perovskites, providing a new platform for investigating the role of the A-cation on the structural and photophysical properties.

Here we report a $2 \mathrm{D}$ tri-layered perovskite $(\mathrm{BA})_{2}(\mathrm{EA})_{2} \mathrm{~Pb}_{3} \mathrm{I}_{10}$ (BA is $n$-butylammonium) which incorporates large EA cation in the lead iodide perovskite cage. The structure features a significantly stretched perovskite cage with elongated $\mathrm{Pb}-\mathrm{I}$ bond lengths and a higher level of 
octahedral distortion compared to the prototypical $(\mathrm{BA})_{2}(\mathrm{MA})_{2} \mathrm{~Pb}_{3} \mathrm{I}_{10}$. To provide a clearer picture of the interplay between the A-cation and the inorganic structure in determining the properties, we synthesized a series of A-cation alloyed $2 \mathrm{D}$ perovskites $(\mathrm{BA})_{2}\left(\mathrm{EA}_{x} \mathrm{MA}_{1-x}\right)_{2} \mathrm{~Pb}_{3} \mathrm{I}_{10}$ and investigated their crystal structures, optical and electronic properties, and excited state dynamics using a range of structural and spectroscopic techniques in combination with theoretical calculations.

The single-crystal X-ray diffraction measurements show that the average $\mathrm{Pb}$-I bond length and the level of octahedral distortion increases with increasing the amount of EA cation (equivalent to increasing the size of A-cation), while the octahedral tilt is retained. Contrary to the bandgap redshift due to less octahedral tilting in $3 \mathrm{D} \mathrm{APbI}_{3}$ with increasing cation size (such as bandgap shift from orthorhombic $\mathrm{CsPbI}_{3}$ to tetragonal $\mathrm{MAPbI}_{3}$ and to cubic $\mathrm{FAPbI}_{3}$ at room temperature, ${ }^{42}$ or bandgap redshift in the alloys with an increasing average cation size ${ }^{43}$, the alloyed 2D perovskites exhibit blue-shifted bandgap with increasing EA content. The bandgap blueshift is consistent with band structure calculations, which point to the crucial role of $\mathrm{Pb}$-I bond length as opposed to octahedral tilting in determining the bandgap of these EA-based halide perovskites. Moreover, the structural evolution with increasing the EA content further leads to gradual photoluminescence (PL) quenching and more asymmetric PL peaks. Transient absorption spectroscopy measurements on these alloys reveal the existence of a broad distribution of trap states below the optical bandgap. The energetic distribution of these trap states is broader with increasing EA content, which likely are responsible for PL peak asymmetry and quenching. These results provide guidelines for rational design of new and more efficient $2 \mathrm{D}$ perovskite materials for optoelectronic applications.

\section{RESULTS AND DISCUSSION}


Crystal structure of $(\mathbf{B A})_{2}(\mathbf{E A})_{2} \mathbf{P b}_{3} \mathbf{I}_{10}$. Single crystals of $(\mathrm{BA})_{2}(\mathrm{EA})_{2} \mathrm{~Pb}_{3} \mathrm{I}_{10}$ were grown from concentrated hydroiodic acid using an off-stoichiometry protocol (see Experimental Section for more details). Crystallographic data and structural refinement information of $(\mathrm{BA})_{2}(\mathrm{EA})_{2} \mathrm{~Pb}_{3} \mathrm{I}_{10}$ are provided in Table S1. The crystal structure consists of three layers of corner-connected $\mathrm{PbI}_{6}{ }^{4-}$ octahedra with a bilayer of BA cations as spacers separating the perovskite slabs (Figure 1a), and the EA cations filling in the perovskite cavities (Figure 1b). The perovskite cages exhibit a combination of short and long $\mathrm{Pb}$-I bonds along the out-of-plane direction (perpendicular to the layers), while almost the same $\mathrm{Pb}$-I bond lengths along the in-plane directions. A view along $c$ direction clearly shows that the structural distortion of the inner layer is different from that of the two outer layers. The inner layer exhibits less out-of-plane octahedral distortion but more in-plane octahedral tilting, while the outer layer displays more out-of-plane octahedral distortion but less in-plane octahedral tilting (Figure 1c). The inner layer can be viewed as templated by two cage EA cations, while the outer layer is templated by one interlayer BA cation and one cage EA cation. As a result, the inorganic framework distorts in a different way to accommodate the one of the possible conformations of these organic cations. The structural characteristics are similar to the previously reported single-cation templated $2 \mathrm{D}$ perovskites $(\mathrm{EA})_{2}(\mathrm{EA})_{2} \mathrm{~Pb}_{3} \mathrm{X}_{10}\left(\mathrm{X}=\mathrm{Cl}^{-}, \mathrm{Br}^{-}\right) .{ }^{39}$ However, the iodide-based compounds have not been reported probably because the EA cation is too small to serve as interlayer spacer for the iodide perovskites. 
Owing to the much larger size of EA (effective radius $r=274 \mathrm{pm}$ ) relative to MA ( $r=217$ $\mathrm{pm})$, the incorporation of EA cation in the cage significantly modulates the structural and bonding properties compared to previously reported 2D structures with MA cation in the cage. To illustrate the unique structural characteristics, we compare the structural parameters and bonding properties of $(\mathrm{BA})_{2}(\mathrm{EA})_{2} \mathrm{~Pb}_{3} \mathrm{I}_{10}$ with the prototypical $(\mathrm{BA})_{2}(\mathrm{MA})_{2} \mathrm{~Pb}_{3} \mathrm{I}_{10}$. The results are summarized in Table 1. $(\mathrm{BA})_{2}(\mathrm{EA})_{2} \mathrm{~Pb}_{3} \mathrm{I}_{10}$ crystallizes in the orthorhombic space group $C m c 2_{1}$ with cell parameters $a=$ 52.0158(16) $\AA, b=8.9727(3) \AA$, and $c=8.9745(3) \AA$, while $(\mathrm{BA})_{2}(\mathrm{MA})_{2} \mathrm{~Pb}_{3} \mathrm{I}_{10}$ crystallizes in the orthorhombic space group $C 2 c b$ with cell parameters $a=8.9275(6) \AA, b=51.959(4) \AA$, and $c=$ 8.8777(6) $\AA .{ }^{44}$ One obvious difference between the two compounds is that the presence of EA 
cation in the cage significantly stretches the $\mathrm{Pb}$-I bond distances, expanding the unit cell of $(\mathrm{BA})_{2}(\mathrm{EA})_{2} \mathrm{~Pb}_{3} \mathrm{I}_{10}$ in the three directions. The $(\mathrm{BA})_{2}(\mathrm{EA})_{2} \mathrm{~Pb}_{3} \mathrm{I}_{10}$ exhibits much longer $\mathrm{Pb}-\mathrm{I}$ bonds compared to any reported 2D lead iodide perovskites with $n=3$ (Table S2). For example, the average $\mathrm{Pb}$-I bond length of $(\mathrm{BA})_{2}(\mathrm{EA})_{2} \mathrm{~Pb}_{3} \mathrm{I}_{10}$ is $3.213 \AA$, while that of $(\mathrm{BA})_{2}(\mathrm{MA})_{2} \mathrm{~Pb}_{3} \mathrm{I}_{10}$ is 3.163 $\AA$. The longest $\mathrm{Pb}$-I bond length in $(\mathrm{BA})_{2}(\mathrm{EA})_{2} \mathrm{~Pb}_{3} \mathrm{I}_{10}$ is $3.458 \AA$ (highlighted as dash bonds in Figure 1b), which is one of the longest bonds in all reported lead iodide perovskites. As a result, the volume of the unit cell increases by $70.6 \AA^{3}$, corresponding to $\sim 1.7 \%$ volume expansion, for $(\mathrm{BA})_{2}(\mathrm{EA})_{2} \mathrm{~Pb}_{3} \mathrm{I}_{10}$ compared to $(\mathrm{BA})_{2}(\mathrm{MA})_{2} \mathrm{~Pb}_{3} \mathrm{I}_{10}$. If only the inorganic framework is considered, the volume expansion is even more significant, as indicated by the $\sim 4.6 \%$ expansion of the perovskite cage volume defined by the volume of the cuboid made up by eight adjacent $\mathrm{Pb}$ atoms at the cuboid corners.

Table 1. Comparison of the structural and bonding parameters between $(\mathrm{BA})_{2}(\mathrm{MA})_{2} \mathrm{~Pb}_{3} \mathrm{I}_{10}$ and $(\mathrm{BA})_{2}(\mathrm{EA})_{2} \mathrm{~Pb}_{3} \mathrm{I}_{10}$.

\begin{tabular}{cccc}
\hline Structure/comparison & $(\mathrm{BA})_{2}(\mathrm{EA})_{2} \mathrm{~Pb}_{3} \mathrm{I}_{10}$ & $(\mathrm{BA})_{2}(\mathrm{MA})_{2} \mathrm{~Pb}_{3} \mathrm{I}_{10}$ & $\begin{array}{c}\text { Difference (EA- } \\
\text { MA) }\end{array}$ \\
\hline Formula weight & 2131.05 & 2103.00 & 28.05 \\
Crystal system & orthorhombic & orthorhombic \\
Space group & $C m c 2_{1}$ & $C 2 c b$ \\
Unit cell dimensions & $a=52.0158(16) \AA$ & $a=8.9275(6) \AA$ \\
& $c=8.9727(3) \AA$ & $b=51.959(4) \AA$ \\
& $\alpha, \beta, \gamma=90^{\circ}$ & $\alpha, \beta, \gamma=90^{\circ}$
\end{tabular}




\begin{tabular}{|c|c|c|c|}
\hline Volume of unit cell $\left(\AA^{3}\right)$ & $4188.6(2)$ & $4118.0(5)$ & $70.6(\sim 1.7 \%)$ \\
\hline $\begin{array}{l}\text { Volume of perovskite cage } \\
\qquad\left(\AA^{3}\right)\end{array}$ & 267.2 & 255.1 & $12.1(\sim 4.7 \%)$ \\
\hline$L_{1}($ cage $)(\AA)$ & 13.274 & 12.876 & $0.398(\sim 3.1 \%)$ \\
\hline$L_{2}$ (spacer) $(\AA)$ & 12.734 & 13.834 & $-1.100(\sim 8.0 \%)$ \\
\hline $\begin{array}{c}\text { Average } \mathrm{Pb}-\mathrm{I} \text { bong length } \\
(\AA)\end{array}$ & 3.213 & 3.163 & $0.050(\sim 1.6 \%)$ \\
\hline $\begin{array}{l}\text { Average quadratic } \\
\text { elongation }(\langle\lambda\rangle)\end{array}$ & 1.00117 & 1.00058 & $5.9 \times 10^{-4}$ \\
\hline $\begin{array}{l}\text { Average bond angle variance } \\
\qquad\left(\operatorname{deg}^{2}\right)\end{array}$ & 19.3 & 4.4 & 14.9 \\
\hline $\begin{array}{c}\text { Average } \mathrm{Pb}-\mathrm{I}-\mathrm{Pb} \text { bond angle } \\
(\mathrm{deg})\end{array}$ & 166 & 170 & -4 \\
\hline
\end{tabular}

In addition to the lattice expansion, the incorporation of EA cation in the cage induces a higher level of structural distortion. In general, structural distortions of the inorganic framework can be categorized into two types. One is the geometrical distortion of the $\mathrm{PbI}_{6}{ }^{4-}$ octahedra themselves, which can be quantified by octahedral distortion parameters of bond length quadratic elongation $(\langle\lambda\rangle)$ and bond angle variance $\left(\sigma^{2}\right)^{45}$

$$
\begin{gathered}
\langle\lambda\rangle=\frac{1}{6} \sum_{\{i=1\}}^{6}\left(\frac{d_{i}}{d_{o}}\right)^{2} \\
\sigma^{2}=\frac{1}{11} \sum_{\{i=1\}}^{12}\left(\alpha_{i}-90\right)^{2}
\end{gathered}
$$


where $d_{i}$ is the $\mathrm{Pb}$-I bond length, $d_{o}$ is the mean $\mathrm{Pb}$-I bond distance, $\alpha_{i}$ is the I-Pb-I bond angles of the octahedra. In an ideal $\mathrm{PbI}_{6}$ octahedron, both $\langle\lambda\rangle$ and $\sigma^{2}$ are equal to 1 . Larger $\langle\lambda\rangle$ indicates a more stretched octahedron, while larger $\sigma^{2}$ indicates higher deviation of $\mathrm{Pb}$ position from the center. The average $\langle\lambda\rangle$ and $\sigma^{2}$ of overall structure $(\mathrm{BA})_{2}(\mathrm{EA})_{2} \mathrm{~Pb}_{3} \mathrm{I}_{10}$ is calculated to be 1.00117 and $19.3 \mathrm{deg}^{2}$, which is higher than that of $(\mathrm{BA})_{2}(\mathrm{MA})_{2} \mathrm{~Pb}_{3} \mathrm{I}_{10}\left(1.00058\right.$ and $\left.4.4 \mathrm{deg}^{2}\right)$, respectively. The other type of structural distortion is the larger global distortion between adjacent octahedra (i.e. octahedral tilting), which can be determined from the $\mathrm{Pb}-\mathrm{I}-\mathrm{Pb}$ bond angle. In an ideal cubic perovskite with no octahedral tilting, the $\mathrm{Pb}-\mathrm{I}-\mathrm{Pb}$ bond angle is equal to $180^{\circ}$. The average $\mathrm{Pb}-\mathrm{I}-$ $\mathrm{Pb}$ angle is $166 \mathrm{deg}$ and 170 deg for $(\mathrm{BA})_{2}(\mathrm{EA})_{2} \mathrm{~Pb}_{3} \mathrm{I}_{10}$ and $(\mathrm{BA})_{2}(\mathrm{MA})_{2} \mathrm{~Pb}_{3} \mathrm{I}_{10}$, respectively, indicating a slightly higher octahedral tilting in the former.

It is also interesting to point out that when switching the A-cation from MA to EA the thickness of the perovskite slab (defined as $L_{1}$ in Figure 1a) is increased slightly from $12.876 \AA$ to 13.276 $\AA$, while the interlayer distance (defined as $L_{2}$ in Figure 1a) is reduced from $13.834 \AA$ to 12.734 $\AA$. This has been considered as an indicator of inherent strain relaxation in 2D structures. ${ }^{37,46}$ Although the incorporation of EA cation in the perovskite cage creates large strain on the inorganic framework, this strain can be readily dissipated into the interlayer space via octahedral distortion of the outer layers. As a result, the BA cations change the molecular conformation to accommodate the distortion. In addition, from the viewpoint of the recent proposed 'lattice mismatch model' ${ }^{46}$ one may expect that substitution of the MA by EA will enhance the initial in-plane strain between the $(\mathrm{BA})_{2} \mathrm{PbI}_{4}$ and 3D_like layers when they are associated to form in-plane coherent interface in a multilayered composite. Although the 3D $\mathrm{EAPbI}_{3}$ structure does not exist, simple considerations based on the Goldschmidt rule predict a 
larger volume for the hypothetic unit cell of $\mathrm{EAPbI}_{3}$ than for the unit cell of $\mathrm{MAPbI}_{3}$ and thus a larger in-plane mismatch with $(\mathrm{BA})_{2} \mathrm{PbI}_{4}$.

Structural evolution of $(\mathbf{B A})_{2}\left(\mathbf{E A}_{x} \mathbf{M} \mathbf{A}_{1-x}\right)_{2} \mathbf{P b}_{3} \mathbf{I}_{10}$ alloys. To better illustrate the influence of A-cation on the structural properties, we further synthesized a series of single-crystal A-cation alloyed $2 \mathrm{D}$ perovskites of $(\mathrm{BA})_{2}\left(\mathrm{EA}_{x} \mathrm{MA}_{1-x}\right)_{2} \mathrm{~Pb}_{3} \mathrm{I}_{10}$ using precursor solutions containing mixed MA and EA cations. The MA to EA ratios determined by ${ }^{1} \mathrm{H}$ NMR measurements on three representative alloys are $0.73 / 0.27,0.55 / 0.45$ and $0.35 / 0.65$, respectively. The determined MA to EA ratio is slightly higher than the ratio in the precursor solution (Figure S1), indicating the inorganic lattice enthalpically prefer MA cation. However, entropic gain will drive the mixing of the two cations. The compounds are described as $\mathrm{MA}_{0.73} \mathrm{EA}_{0.27}, \mathrm{MA}_{0.55} \mathrm{EA}_{0.45}$ and $\mathrm{MA}_{0.35} \mathrm{EA}_{0.65}$ for the following discussion. Figure S2 shows the calculated tolerance factor as a function of EA content. Using the tolerance factor of $\mathrm{FAPbI}_{3}$ as a reference point, the ability to incorporate large EA cation with content exceeding 0.62 stems from the relaxed tolerance factor requirement in $2 \mathrm{D}$ perovskites. Crystal structures of these alloys were solved using single-crystal X-ray diffraction for structural comparison. Because the MA and EA cations are highly disordered in our singlecrystal X-ray diffraction data, we cannot distinguish and model them accurately. Therefore, the structures were refined as either MA or EA as the A-cation, depending on which one gives better refinement, but this will not influence the structures of the inorganic framework. The crystallographic data and structural refinement information are provided in Table S3. These alloys crystallize in the monoclinic space group $C c$, which has a lower symmetry than the pure A-cation structures.

Cation alloying can be viewed as an effective approach to tune the average size of A-cation. Figure 2 shows the trends of several structural parameters as the EA/MA ratio (or the average size 
of A-cation) increases. For example, the average $\mathrm{Pb}-\mathrm{I}$ bond length and cage volume increase with increasing the EA/MA ratio (Figure 2a). The thickness of the perovskite slab $\left(L_{1}\right)$ also increases with increasing the EA/MA ratio, while the interlayer distance decreases (Figure 2b). The interlayer distance is indeed changing as a result of a strain along the stacking axis opposite to the in-plane initial strain. ${ }^{46}$ We consider this as an indicator of increasing strain in the alloys with more EA cations in the cages. Furthermore, incorporation of more EA cations induces a larger deviation from the ideal $\mathrm{PbI}_{6}{ }^{4-}$ octahedron, as demonstrated by the increasing $\langle\lambda\rangle$ and $\sigma^{2}$ (Figure 2c). Interestingly, the average octahedral tilting angle remains quite similar (Figure 2d), which appears to slightly increase and then decrease. In fact, the even slightly smaller tilting angle in the EA structure than MA structure is counterintuitive, because one may expect that EA cation will stretch $\mathrm{Pb}-\mathrm{I}-\mathrm{Pb}$ bond angle (make it closer to $180^{\circ}$ ) due to the much larger effective radius, similarly to the structural evolution from orthorhombic $\mathrm{CsPb}_{3}$ to tetragonal $\mathrm{MAPbI}_{3}$ then to cubic $\mathrm{FAPbI}_{3}$ (Table S4). However, octahedral tilting is an efficient way to relax internal stress ${ }^{46}$ related to the formation of the multilayered composite. These two effects play in opposite directions. 


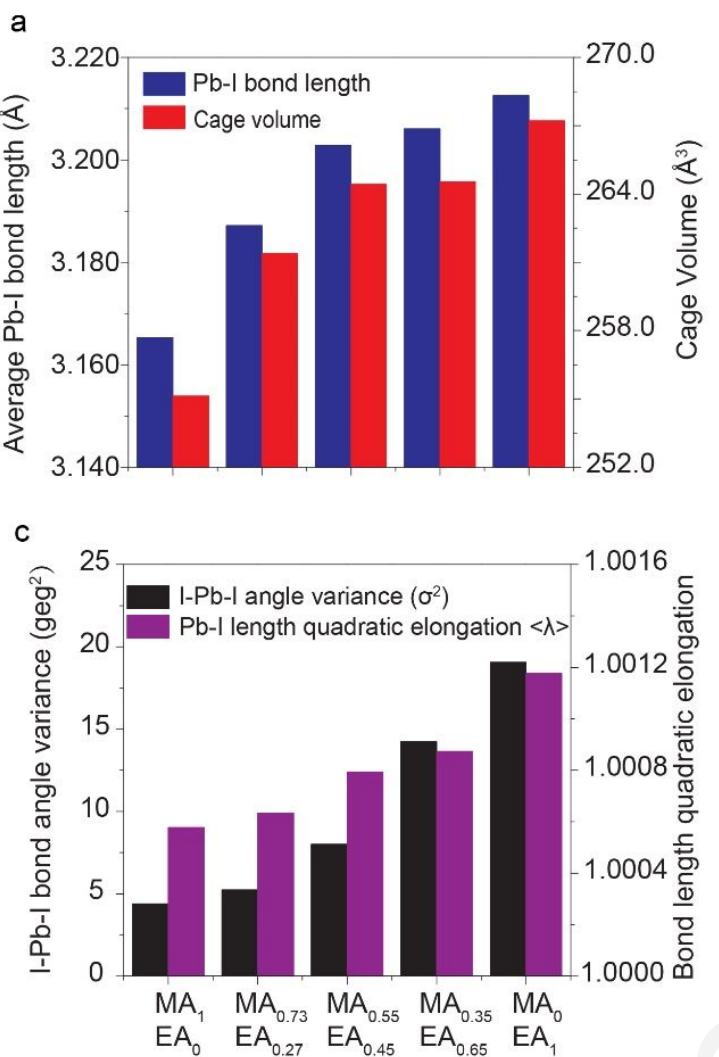

Stoichiometry b

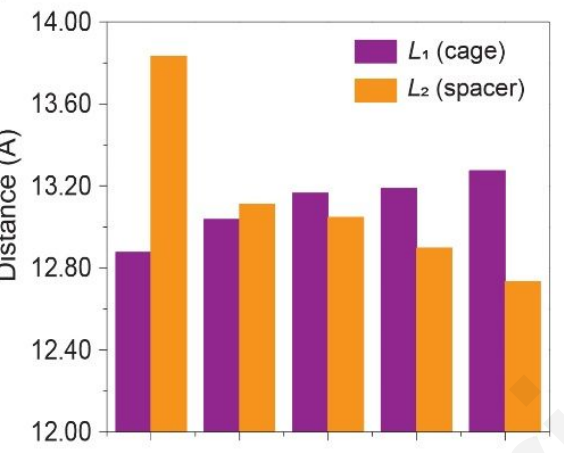

d

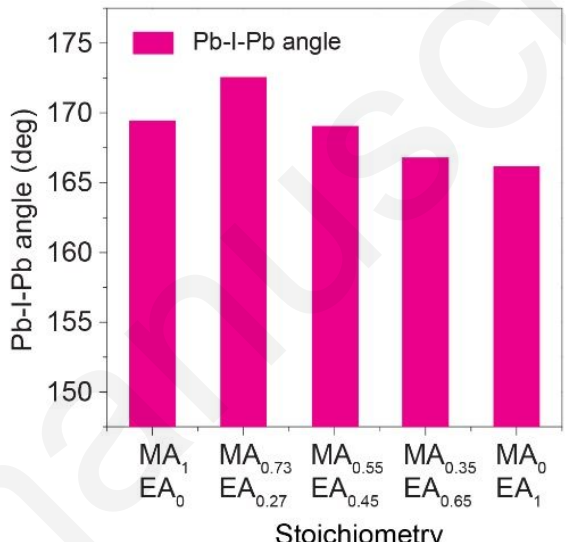

Figure 2. Structural properties of $(\mathrm{BA})_{2}\left(\mathrm{EA}_{x} \mathrm{MA}_{1-x}\right)_{2} \mathrm{~Pb}_{3} \mathrm{I}_{10}$ alloys. The trends of (a) average $\mathrm{Pb}-\mathrm{I}$ bond length and cage volume, (b) thickness of the perovskite slab $\left(L_{1}\right)$ and interlayer spacer distance $\left(L_{2}\right)$, (c) average I-Pb-I angle variance and $\mathrm{Pb}$-I length quadratic elongation, (d) average $\mathrm{Pb}-\mathrm{I}-\mathrm{Pb}$ angle as a function of alloying degree.

The above comparisons are focused on the average of overall structure (i.e. two outer layers + one inner layer). However, it is important to point out that the inner and outer layers exhibit distinctive structural properties. Figure 3 provides the trends of the octahedral distortion and octahedral tilt of the inner and outer layers as a function of alloying degree. The outer layer exhibits higher octahedral distortion than the inner layer, as demonstrated by larger $\langle\lambda\rangle$ and $\sigma^{2}$ in all compounds. Both the inner and outer layers show an increasing trend of the $\sigma^{2}$ with increasing the 
EA content (Figure 3a). The $\langle\lambda\rangle$ of the inner layer is slightly reduced in the EA alloys compared to the MA structure (Figure 3b). Therefore, the increasing trend of the $\langle\lambda\rangle$ in the overall structure is mainly determined by the outer layer, which exhibits larger $\langle\lambda\rangle$ with an increasing EA content (Figure 3b). This is because the incorporation of EA cations in the cage induces a greater impact on elongating the longest $\mathrm{Pb}-\mathrm{I}$ bonds (highlighted as dash lines in Figure 1b) than the other bonds.
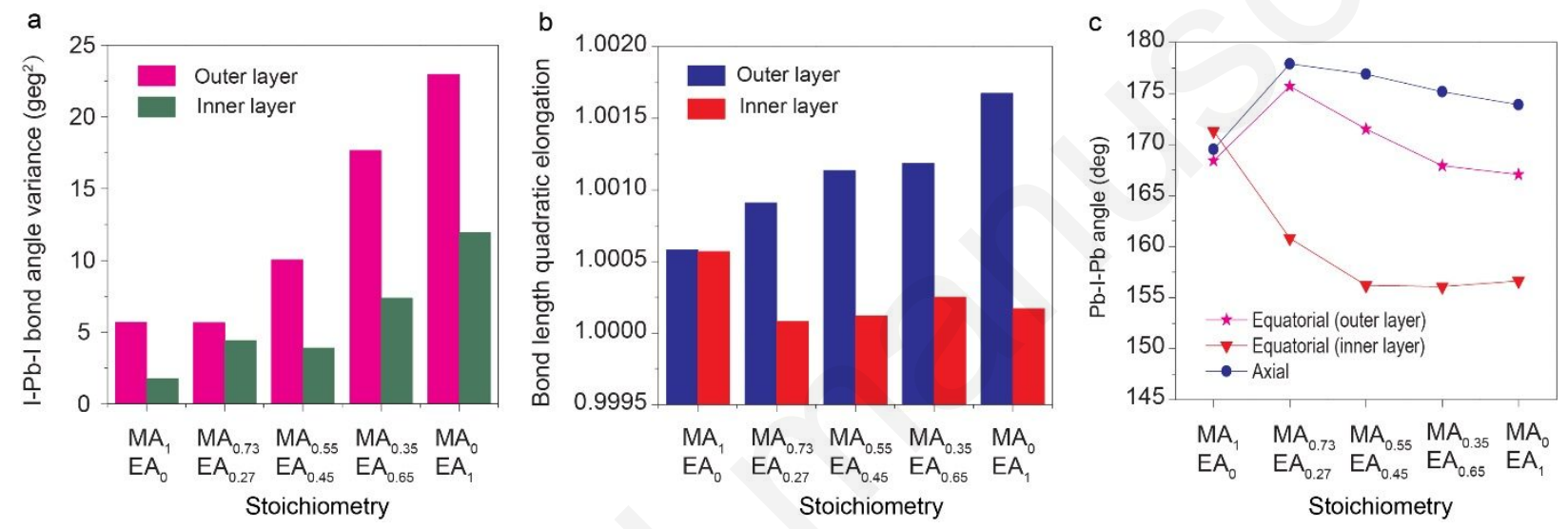

Figure 3. Structural properties of the inner and outer layers in the set of $(\mathrm{BA})_{2}\left(\mathrm{EA}_{x} \mathrm{MA}_{1-x}\right)_{2} \mathrm{~Pb}_{3} \mathrm{I}_{10}$. The trends of (a) average I-Pb-I angle variance, (b) Pb-I length quadratic elongation, (c) average equatorial $\mathrm{Pb}-\mathrm{I}-\mathrm{Pb}$ angle of the inner and outer layers as a function of alloying degree. Panel $\mathrm{c}$ also shows the trend of axial $\mathrm{Pb}-\mathrm{I}-\mathrm{Pb}$ angle.

Due to the anisotropic 2D structure, we categorized the $\mathrm{Pb}-\mathrm{I}-\mathrm{Pb}$ angles into two groups: equatorial angle and axial angle (see Figure $1 \mathrm{~b}$ for definition) for the comparison of octahedral tilt. As shown in Figure 3c, the average axial angle increases from 170 deg (MA) to 178 deg $\left(\mathrm{MA}_{0.73} \mathrm{EA}_{0.27}\right)$ and then slightly decreases to $174 \mathrm{deg}(\mathrm{EA})$. The average equatorial angle of the outer layer also increases from $168 \mathrm{deg}(\mathrm{MA})$ to $176 \mathrm{deg}\left(\mathrm{MA}_{0.73} \mathrm{EA}_{0.27}\right)$ and then decreases to 167 
deg (EA). However, the average equatorial angle of the inner layer exhibits an opposite trend, which dramatically decreases from $170 \mathrm{deg}(\mathrm{MA})$ to $156 \mathrm{deg}\left(\mathrm{MA}_{0.55} \mathrm{EA}_{0.45}\right)$ and then remains almost unchanged. The results show that the incorporation of the EA cations in the cage induces a larger in-plane tilt in the inner layer. However, when the overall structures are considered, this effect is partially cancelled due to the smaller in-plane tilt of the outer layer and the smaller tilt along the stacking direction. Because the inner layer is templated by the two cage EA cations, the larger in-plane tilt of the inner layer is probably due to steric and Coulombic interactions between the EA cations and inorganic framework. For example, because the EA cation exhibits a more anisotropic shape than the MA cation, the octahedra of the inner layer have to tilt in a certain way to accommodate the EA configuration (as highlighted in Figure 1c).

Optical properties of $(\mathbf{B A})_{2}\left(\mathbf{E A}_{x} \mathbf{M A} A_{1-x}\right)_{2} \mathbf{P b}_{3} \mathbf{I}_{10}(x=0-1)$. Absorption spectra collected on exfoliated single crystals show a continuous blue shift of the excitonic absorption peak as the EA content increases (Figure 4a). Absorption spectra of 15 randomly selected exfoliated crystals of $\mathrm{MA}_{0.55} \mathrm{EA}_{0.45}$ show close excitonic absorption peaks, confirming no phase segregation into the MA and EA structures (Figure S3). PL spectra of the corresponding bulk single crystals also exhibit blue shift (Figure 4b). The tuning of the bandgap can also be seen in the crystal color, which gradually changes from red to black with decreasing the EA content (Figure S4). The $(\mathrm{BA})_{2}(\mathrm{EA})_{2} \mathrm{~Pb}_{3} \mathrm{I}_{10}$ has a PL emission peak located at $585 \mathrm{~nm}$ (corresponding to an optical bandgap of $2.12 \mathrm{eV})$, which is significantly blue shifted from that of $(\mathrm{BA})_{2}(\mathrm{MA})_{2} \mathrm{~Pb}_{3} \mathrm{I}_{10}$ at $620 \mathrm{~nm}(2.00$ $\mathrm{eV})$. In fact, $(\mathrm{BA})_{2}(\mathrm{EA})_{2} \mathrm{~Pb}_{3} \mathrm{I}_{10}$ exhibits the highest bandgap among all previously reported $n=3$ lead iodide 2D perovskites (Table S2). We note that the PL spectra collected in the interior and edge of the $(\mathrm{BA})_{2}(\mathrm{EA})_{2} \mathrm{~Pb}_{3} \mathrm{I}_{10}$ are almost unchanged (Figure $\left.\mathrm{S} 5\right)$. Figure $4 \mathrm{c}$ shows the plot of 
excitonic absorption/emission peaks as a function of $x$ value, conforming to the Vegard's law approximation (fitting lines).

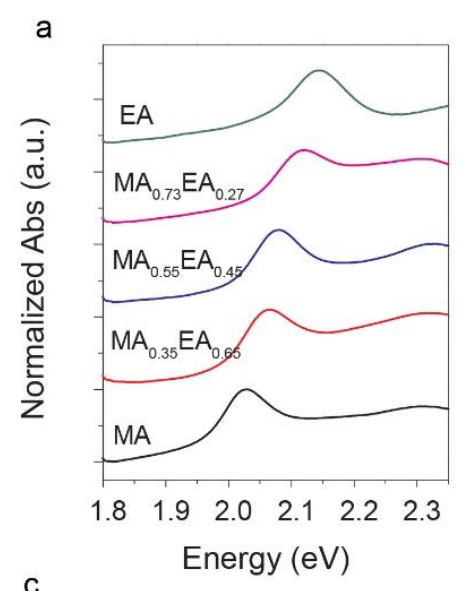

C

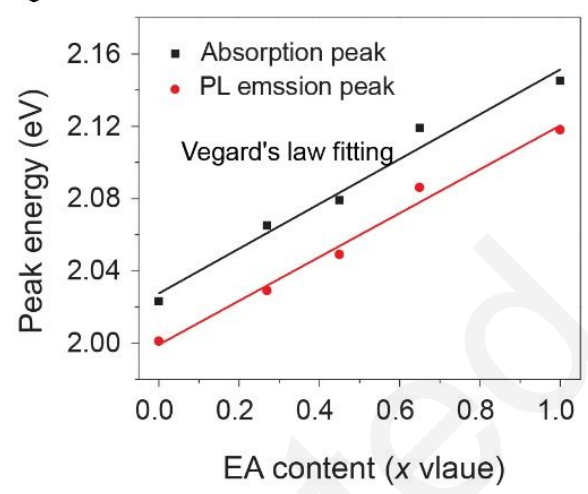

b

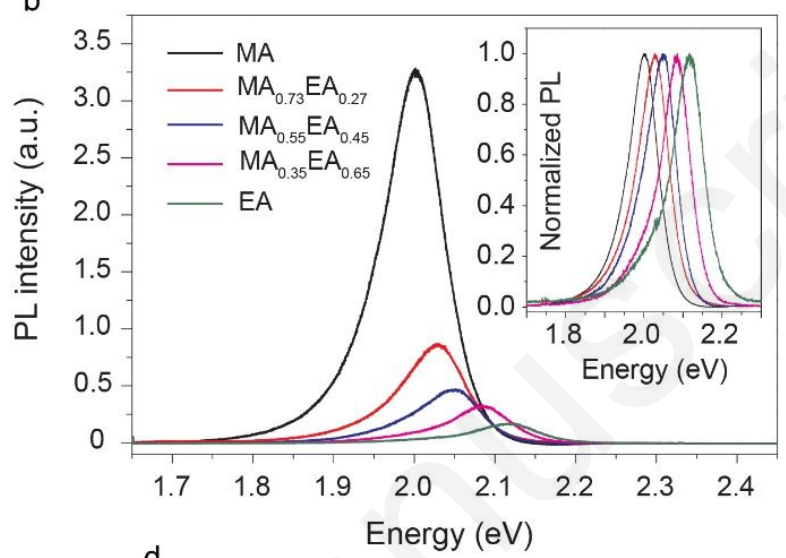

d

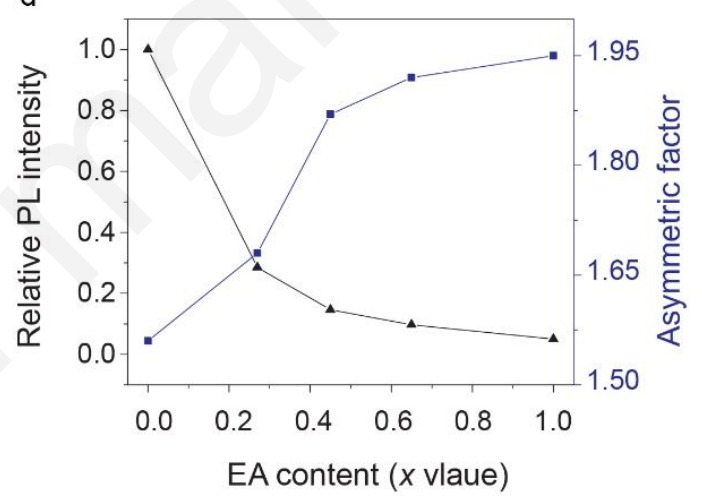

Figure 4. Optical properties of the $(\mathrm{BA})_{2}\left(\mathrm{EA}_{x} \mathrm{MA}_{1-x}\right)_{2} \mathrm{~Pb}_{3} \mathrm{I}_{10}$ alloys. (a) Absorption spectra of the alloys. (b) PL spectra of the alloys. Normalized spectra are shown in the inset. (c) The plot of excitonic absorption peak and emission peak as a function of the EA content. The straight lines are the fits using the Vegard's law (d) Plot of relative PL intensity and PL asymmetric factor as a function of the EA content. 
Besides the tuning of the bandgap, the PL intensity is quenched in the structure with an increasing EA fraction (i.e. $x$ value) (Figure $4 \mathrm{~b}$ and $4 d$ ). As an example, the PL intensity of $(\mathrm{BA})_{2}(\mathrm{EA})_{2} \mathrm{~Pb}_{3} \mathrm{I}_{10}$ is about 20 times weaker than that of $(\mathrm{BA})_{2}(\mathrm{MA})_{2} \mathrm{~Pb}_{3} \mathrm{I}_{10}$. Note that the PL spectra were collected on bulk single crystals with freshly cleaved surfaces under the same laser excitation power density. Such strong PL quenching seems to be associated with the higher octahedral distortion and elongated $\mathrm{Pb}$-I bond length, as will be discussed below. Another interesting characteristic is that, each PL spectrum displays an asymmetric line-shape, tailing to lower energy. We introduce an asymmetric factor to quantify the PL tailing effect:

$$
\mathrm{A}_{\mathrm{s}}=\mathrm{H}_{\mathrm{r}} / \mathrm{H}_{\mathrm{b}}
$$

where $\mathrm{H}_{\mathrm{b}}$ and $\mathrm{H}_{\mathrm{r}}$ are the peak half-widths at $10 \%$ of the peak height. $\mathrm{H}_{\mathrm{b}}$ corresponds to the blue (higher energy) side, while $\mathrm{H}_{\mathrm{r}}$ characterizes the red (lower energy) side relative to the peak position. As shown in Figure 4d, the asymmetric factor increases as the EA content increases and is anti-correlated with the relative PL intensity. The low-energy tail in the static PL spectra can be attributed to the radiative recombination of trap states below the bandgaps, as has been previously suggested. ${ }^{47}$ Further investigation of the trap states is discussed in a separate section below using ultrafast spectroscopic techniques.

Having characterized the structural and optical properties, we turn to understand and derive the structure-property relationship. Table 2 summarizes the optical and structural properties of the set of $(\mathrm{BA})_{2}\left(\mathrm{EA}_{x} \mathrm{MA}_{1-x}\right)_{2} \mathrm{~Pb}_{3} \mathrm{I}_{10}$. Optical transitions in perovskite materials occur between filled $\mathrm{Pb}(6 \mathrm{~s})-\mathrm{I}(5 \mathrm{p})$ hybrid orbitals and empty $\mathrm{Pb}(6 \mathrm{p})$ orbitals of the inorganic layer (vide infra). As a result, the optical bandgap can be correlated with the degree of anti-bonding overlap between the $\mathrm{Pb}(6 \mathrm{~s})$ and $\mathrm{I}(5 \mathrm{p})$ orbitals, which is strongly modulated by the bonding parameters such as $\mathrm{Pb}-\mathrm{I}-\mathrm{Pb}$ bond angle and $\mathrm{Pb}-\mathrm{I}$ bond length. ${ }^{16}$ While the A-cations do not directly contribute to the electronic 
band structure close to the band edges, they have a strong influence on the tilting of $\mathrm{PbI}_{6}{ }^{4-}$ octahedra and in turn affect the degree of orbital overlap between $\mathrm{Pb}$ and I orbitals. For example, there is a systematic decreasing trend in the bandgap with increasing the size of A-cation in the perovskite phases of $3 \mathrm{D} \mathrm{APbI}_{3}(\mathrm{~A}=\mathrm{Cs}, \mathrm{MA}, \mathrm{FA})$ at room temperature (Table $\left.\mathrm{S} 4\right)$. This is because the octahedral tilting decreases (or Pb-I-Pb bond angle increases) while the Pb-I bond length almost remains unchanged as the cation size increases, leading to an increased overlap of the $\mathrm{Pb}(6 \mathrm{~s})$ and $\mathrm{I}(5 \mathrm{p})$ orbitals and in turn a more destabilized valence band..$^{15,42}$

Table 2. Comparison of optical properties and structural parameters for $(\mathrm{BA})_{2}\left(\mathrm{EA}_{x} \mathrm{MA}_{1-x}\right)_{2} \mathrm{~Pb}_{3} \mathrm{I}_{10}$

\begin{tabular}{llllll}
\hline & EA & $\mathbf{E A}_{\mathbf{0 . 6 5}} \mathbf{M A}_{\mathbf{0 . 3 5}}$ & $\mathbf{E A}_{\mathbf{0 . 4 5}} \mathbf{M A}_{\mathbf{0 . 5 5}}$ & $\mathbf{E A}_{\mathbf{0 . 2 7}} \mathbf{M A}_{\mathbf{0 . 7 3}}$ & MA \\
\hline Absorption peak $(\mathrm{eV})$ & 2.145 & 2.119 & 2.079 & 2.065 & 2.023 \\
PL emission $(\mathrm{eV})$ & 2.118 & 2.086 & 2.049 & 2.029 & 2.001 \\
Relative PL intensity & 0.050 & 0.097 & 0.146 & 0.285 & 1 \\
PL asymmetric factor & 1.95 & 1.92 & 1.87 & 1.68 & 1.56 \\
Ave. Pb-I bond length $(\AA)$ & 3.213 & 3.206 & 3.203 & 3.178 & 3.165 \\
Ave. cage volume $\left(\AA^{3}\right)$ & 267.2 & 264.5 & 264.4 & 259.5 & 255.1 \\
Ave. Pb-I-Pb bond angle $\left({ }^{\circ}\right)$ & 166 & 167 & 169 & 172 & 169 \\
Quadratic elongation $(\langle\lambda\rangle)$ & 1.00117 & 1.00087 & 1.00079 & 1.00063 & 1.00058 \\
Bond angle variance $\left(\sigma^{2}, \mathrm{deg}^{2}\right)$ & 19.3 & 14.2 & 8.0 & 5.8 & 4.4 \\
\hline
\end{tabular}

Interestingly, the average octahedral tilting of the overall structure in the set of $(\mathrm{BA})_{2}\left(\mathrm{EA}_{x} \mathrm{MA}_{1-x}\right)_{2} \mathrm{~Pb}_{3} \mathrm{I}_{10}$ alloys remains similar. The wider optical bandgap can thus be attributed 
to the gradually increasing $\mathrm{Pb}$-I bond elongation which leads to less overlap between the electron wave functions of the $\mathrm{Pb}(6 \mathrm{~s})$ and $\mathrm{I}(5 \mathrm{p})$ orbitals and narrower band widths. In fact, the trend is consistent with high-pressure studies on 2D perovskites, which show bandgap redshift with decreasing $\mathrm{Pb}$-I bond length under pressure. ${ }^{48}$ The alloying of EA cation into the cage acts like "negative chemical pressure" to expand the crystal structure, which can be a generic approach to tune the optoelectronic properties of $2 \mathrm{D}$ perovskites. ${ }^{48}$ Similar bandgap blueshift in the 3D "hollow" perovskites with increasing $\mathrm{Pb}$-I bond lengths has also been observed. ${ }^{34,35}$

Another interesting structure-property relationship is that the PL quenching seems to correlate with $\mathrm{Pb}-\mathrm{I}$ bond length and/or individual $\mathrm{PbI}_{6}^{4-}$ octahedral distortion. PL efficiency is determined by the relative ratio of radiative recombination rate to non-radiative recombination rate. ${ }^{49}$ The radiative recombination rates of these alloys are expected to be similar, as they likely have similar exciton binding energies. Therefore, the pronounced PL quenching which usually indicates poor photophysical properties in a direct band gap semiconductor might originate from more non-radiative recombination losses in the structures with higher EA content. Comparable photophysical properties have been reported in the perovskite phases of orthorhombic $\mathrm{CsPbI}_{3}$, tetragonal $\mathrm{MAPbI}_{3}$, and cubic $\mathrm{FAPbI}_{3}$, which exhibit almost ideal $\mathrm{PbI}_{6}{ }^{4-}$ octahedra and constant $\mathrm{Pb}-\mathrm{I}$ bond length but different octahedral tilting (Table S4). In conjunction with the observations here, the photophysical properties of these $2 \mathrm{D}$ perovskite materials appear to be mostly governed by the $\mathrm{Pb}$-I bond length and/or octahedral distortion, with no noticeable effect of octahedral tilting.

Electronic structure and dielectric properties. We next consider how the A-site cations affect the electronic structure and dielectric properties from a theoretical perspective. In this respect, we first performed Density Functional Theory (DFT) based calculations using the PBE functional and including spin-orbit coupling (SOC), which will be the default level of theory if not 
otherwise stated. Figure $5 \mathrm{a}$ and $5 \mathrm{~b}$ compare the computed band structures of $(\mathrm{BA})_{2}(\mathrm{EA})_{2} \mathrm{~Pb}_{3} \mathrm{I}_{10}$ and $(\mathrm{BA})_{2}(\mathrm{MA})_{2} \mathrm{~Pb}_{3} \mathrm{I}_{10}$. Both band structures present an almost direct bandgap at $\Gamma$, and the calculated bandgaps are $0.86 \mathrm{eV}$ and $0.50 \mathrm{eV}$ for the $\mathrm{EA}$ and MA structure, respectively. In $(\mathrm{BA})_{2}(\mathrm{EA})_{2} \mathrm{~Pb}_{3} \mathrm{I}_{10}$, a slightly indirect band gap appears owing to the breaking of symmetry along $\Gamma$-X direction (not shown). The slight shift of valence band maxima (VBM) from $\Gamma$ points to possible Rashba effect due to the giant SOC of $\mathrm{Pb}$ atom. ${ }^{50}$ Moreover, the band structures of both compounds show that dispersive bands are only present in the $2 \mathrm{D}$ plane while flat bands occur along $\Gamma$-Y. This suggests little or no electronic coupling along the direction that corresponds to the layer stacking axis.
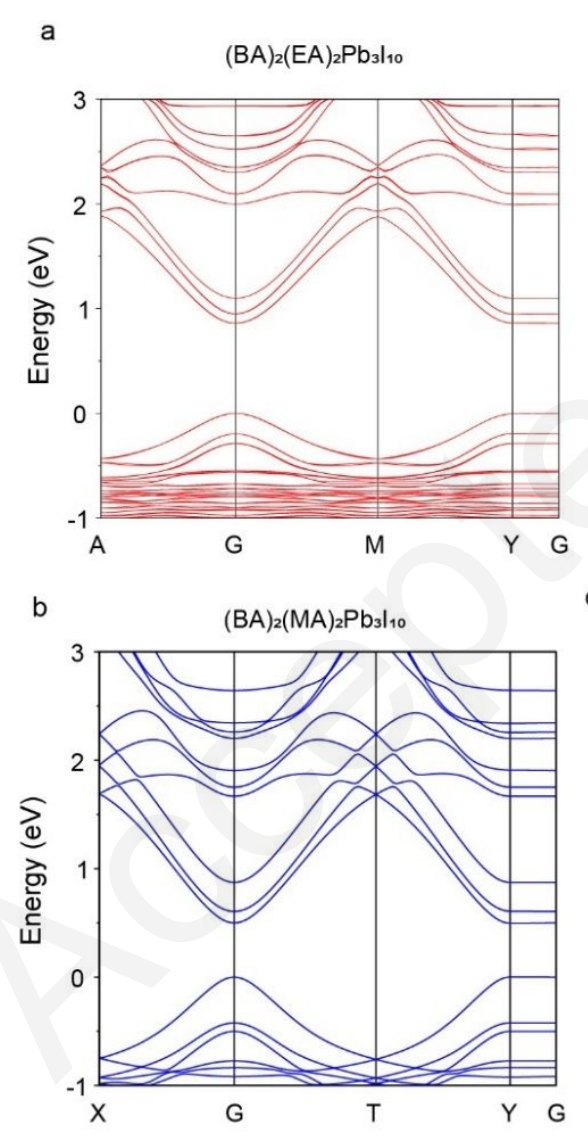
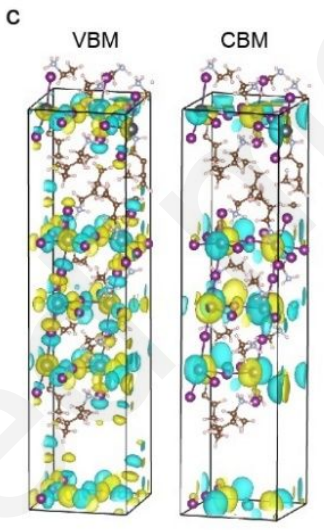

d

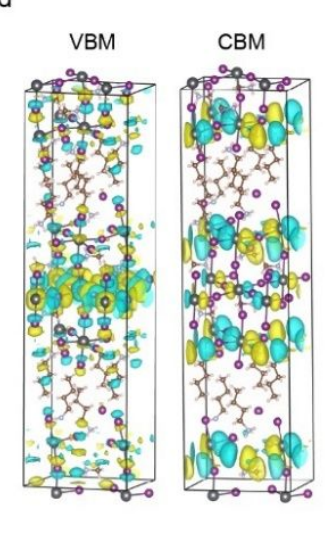

e Свм1-2 +8.

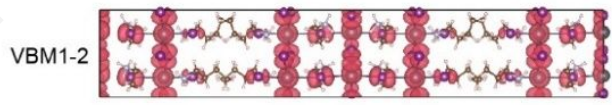
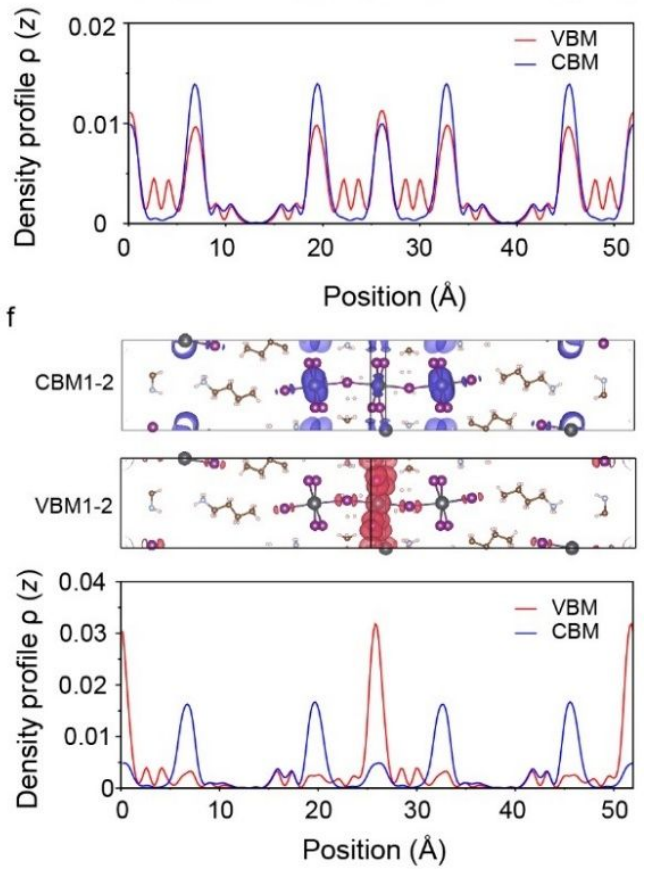
Figure 5. Comparison of electronic band structures of $(\mathrm{BA})_{2}(\mathrm{EA})_{2} \mathrm{~Pb}_{3} \mathrm{I}_{10}$ and $(\mathrm{BA})_{2}(\mathrm{MA})_{2} \mathrm{~Pb}_{3} \mathrm{I}_{10}$. Calculated electronic band structures including SOC of (a) $(\mathrm{BA})_{2}(\mathrm{EA})_{2} \mathrm{~Pb}_{3} \mathrm{I}_{10}$ and (b) $(\mathrm{BA})_{2}(\mathrm{MA})_{2} \mathrm{~Pb}_{3} \mathrm{I}_{10}$. Wave-functions computed without SOC at $\Gamma$ for (c) $(\mathrm{BA})_{2}(\mathrm{EA})_{2} \mathrm{~Pb}_{3} \mathrm{I}_{10}$ and (d) $(\mathrm{BA})_{2}(\mathrm{MA})_{2} \mathrm{~Pb}_{3} \mathrm{I}_{10}$, show the orbital hybridizations at VBM and CBM. Local density of states computed with SOC at VBM and CBM for (e) $(\mathrm{BA})_{2}(\mathrm{EA})_{2} \mathrm{~Pb}_{3} \mathrm{I}_{10}$ and (f) $(\mathrm{BA})_{2}(\mathrm{MA})_{2} \mathrm{~Pb}_{3} \mathrm{I}_{10}$. The density profiles of the two structures along the stacking direction are also shown. All results have been obtained using the PBE functional.

The DFT predicted bandgaps are underestimated compared to the experimental results as expected when using the PBE functional and taking SOC into account. We further used the recently reported Tran-Blaha-Modified Becke-Johnson potential optimized for 2D perovskites to improve the accuracy of bandgap prediction (ppTB-mBJ). ${ }^{51}$ Using ppTB-mBJ with the organic cations substituted by Cs (see Ref. ${ }^{51}$ for more details), the calculated bandgaps become $2.62 \mathrm{eV}$ and 2.53 $\mathrm{eV}$ for $(\mathrm{BA})_{2}(\mathrm{EA})_{2} \mathrm{~Pb}_{3} \mathrm{I}_{10}$ and $(\mathrm{BA})_{2}(\mathrm{MA})_{2} \mathrm{~Pb}_{3} \mathrm{I}_{10}$, respectively, which are in better agreement with the experiment given that excitonic effects are not considered. Overall, regardless of the level of theory, $(\mathrm{BA})_{2}(\mathrm{EA})_{2} \mathrm{~Pb}_{3} \mathrm{I}_{10}$ exhibits a larger bandgap compared to $(\mathrm{BA})_{2}(\mathrm{MA})_{2} \mathrm{~Pb}_{3} \mathrm{I}_{10}$.

We next plot the wave functions to highlight the nature of electronic states at the band edges. Wave functions at the $\Gamma$ point show an antibonding hybridization between $\mathrm{Pb}(6 \mathrm{~s})$ and $\mathrm{I}(5 \mathrm{p})$ orbitals at the VBM while the conduction band minima $(\mathrm{CBM})$ is mainly made of bonding type between $\mathrm{Pb}(6 \mathrm{p})$ states (see Figure 5c and 5d for the EA and MA structure, respectively). Comparing the two structures, we find that the $\mathrm{CBM}$ is less stabilized in $(\mathrm{BA})_{2}(\mathrm{EA})_{2} \mathrm{~Pb}_{3} \mathrm{I}_{10}$ because the longer $\mathrm{Pb}$ $\mathrm{Pb}$ distances result in weaker bonding interactions and reduced bandwidth. Similarly, VBM is also less destabilized in $(\mathrm{BA})_{2}(\mathrm{EA})_{2} \mathrm{~Pb}_{3} \mathrm{I}_{10}$ due to weaker anti-bonding interactions associated with 
longer Pb-I bonds. The combined effect of less stabilized CBM and less destabilized VBM in $(\mathrm{BA})_{2}(\mathrm{EA})_{2} \mathrm{~Pb}_{3} \mathrm{I}_{10}$ therefore results in the wider bandgap.

As mentioned above, in $(\mathrm{BA})_{2}(\mathrm{EA})_{2} \mathrm{~Pb}_{3} \mathrm{I}_{10}$, the bands are less dispersive than in $(\mathrm{BA})_{2}(\mathrm{MA})_{2} \mathrm{~Pb}_{3} \mathrm{I}_{10}$ as can be inferred from their band widths in Figure $5 \mathrm{a}-\mathrm{b}$. That is, the extent of orbital overlap as discussed above generally defines the electronic bandwidth. As it is clearly shown in Figure 5a and 5b, the band widths of the VB as well as the CB for the EA compound are much narrower. Accordingly, the calculated reduced effective masses (using ppTB-mBJ) are larger for $(\mathrm{BA})_{2}(\mathrm{EA})_{2} \mathrm{~Pb}_{3} \mathrm{I}_{10}\left(\sim 0.34 m_{0}\right.$ to $\left.0.69 m_{0}\right)$ as compared to $(\mathrm{BA})_{2}(\mathrm{MA})_{2} \mathrm{~Pb}_{3} \mathrm{I}_{10}\left(\sim 0.20 m_{0}\right)$ (Table $\mathrm{S} 5)$. We note that the predicted reduced mass of $(\mathrm{BA})_{2}(\mathrm{MA})_{2} \mathrm{~Pb}_{3} \mathrm{I}_{10}$ is in good agreement with the experimentally reported $0.201 m_{0}$ using magneto-absorption experiments ${ }^{52}$ whereas that of $(\mathrm{BA})_{2}(\mathrm{EA})_{2} \mathrm{~Pb}_{3} \mathrm{I}_{10}$, for which no experimental data is currently available, appears to be much higher (note, ppTB-mBJ generally overestimates the effective masses, see Ref. ${ }^{51}$ ). These results suggest that photogenerated carriers are probably less mobile in $(\mathrm{BA})_{2}(\mathrm{EA})_{2} \mathrm{~Pb}_{3} \mathrm{I}_{10}$ than in $(\mathrm{BA})_{2}(\mathrm{MA})_{2} \mathrm{~Pb}_{3} \mathrm{I}_{10}$.

The localization of the carriers can influence the recombination process of the generated electron-hole pairs. In Figure 5e and 5f, we plot the local density of states (LDOS) and their profiles for both compounds at VBM and CBM to show the spatial localization of holes and electrons, considering the static averaged crystallographic structured. In $(\mathrm{BA})_{2}(\mathrm{MA})_{2} \mathrm{~Pb}_{3} \mathrm{I}_{10}$, holes (at VBM) are localized on the inner layer whereas the electrons (at CBM) appear at the outer layers. $^{52}$ In contrast, both holes and electrons are delocalized on the three layers for $(\mathrm{BA})_{2}(\mathrm{EA})_{2} \mathrm{~Pb}_{3} \mathrm{I}_{10}$. This suggests that generated hole-electron pairs are probably spatially more evenly distributed in $(\mathrm{BA})_{2}(\mathrm{EA})_{2} \mathrm{~Pb}_{3} \mathrm{I}_{10}$ as compared to $(\mathrm{BA})_{2}(\mathrm{MA})_{2} \mathrm{~Pb}_{3} \mathrm{I}_{10}$. The origin of these different spatial localizations is discussed in the supporting information. In order to better gauge 
By applying the composite approach, detailed in Refs ${ }^{12,54}$, we obtained the band energy alignment between the inorganic well and the organic spacer barrier. The ppTB-mBJ bandgaps were used for constructing the conduction band alignment (Figure S6). The confinement potentials $\left(V_{\mathrm{h}}\right.$ for holes, $V_{\mathrm{e}}$ for electrons) are more balanced in $(\mathrm{BA})_{2}(\mathrm{EA})_{2} \mathrm{~Pb}_{3} \mathrm{I}_{10}(2.6 \mathrm{eV}$ versus $2.1 \mathrm{eV})$ than in $(\mathrm{BA})_{2}(\mathrm{MA})_{2} \mathrm{~Pb}_{3} \mathrm{I}_{10}(3.3 \mathrm{eV}$ versus $1.5 \mathrm{eV})$. Figure $\mathrm{S} 7$ shows high-frequency dielectric constant profiles $\left[\varepsilon_{\infty}(\mathrm{z})\right]$ along the stacking axis for the two compounds. $\varepsilon_{\infty}$ varies from 2.4 [2.2] for $(\mathrm{BA})_{2}(\mathrm{EA})_{2} \mathrm{~Pb}_{3} \mathrm{I}_{10}\left[(\mathrm{BA})_{2}(\mathrm{MA})_{2} \mathrm{~Pb}_{3} \mathrm{I}_{10}\right]$ in the organic spacer layer to 5.3 [5.1] in the inorganic layer. The two compounds present similar dielectric contrasts between the inorganic and the organic layers, which may suggest similar exciton binding energies in the two structures. The slightly different $\varepsilon_{\infty}$ in $(\mathrm{BA})_{2}(\mathrm{EA})_{2} \mathrm{~Pb}_{3} \mathrm{I}_{10}$ can be understood by the volumetric expansion of inorganic layers and the compression of organic spacer layers as compared to (BA) $)_{2}(\mathrm{MA})_{2} \mathrm{~Pb}_{3} \mathrm{I}_{10}$. Nevertheless, the dielectric environment is similar in the two compounds.

Excited state dynamics. We further studied the excited state dynamics using ultrafast transient absorption (TA) spectroscopy. Except for a few reports, ${ }^{47}$ we note that the excited state dynamics of 2D perovskites with $n>1$ remain largely unexplored. Figure 6 shows the normalized TA spectra of $(\mathrm{BA})_{2}\left(\mathrm{EA}_{x} \mathrm{MA}_{1-x}\right)_{2} \mathrm{~Pb}_{3} \mathrm{I}_{10}(x=0,0.27,0.45,0.67,1)$ obtained with $2.41 \mathrm{eV}$ pump and broadband probe (1.74-2.28 eV) on exfoliated single crystals. For all five compositions, the 
TA spectra largely resemble each other. There are four features to pay attention to: (1) a strong ground state bleaching (GSB) at the bandgap, (2) a short-lived excited stated absorption (ESA) below the bandgap, which is most prominent in the 0.40 -ps cut and disappeared before $0.80 \mathrm{ps}$, (3) a long-lived ESA above the bandgap, the intensity of which remains largely unchanged within the first $8 \mathrm{ps}$, and (4) a weak bleaching below the bandgap, which becomes visible after the overlapping ESA disappears near $0.8 \mathrm{ps}$. The relative locations and shapes of the four features do not change much across the entire series of samples we made, indicating similar electronic structures and almost identical mechanisms behind the excited state dynamics, which agrees with the band structure calculations conducted in the section above. The fact that no overlap occurred between all five spectra, along with the structural characterization we presented above, confirm the pure nature of the $n=3$ structure (i.e. absence of other $n$-value structures) and the uniform cation alloying. 
Normalized $(\Delta T / T)$
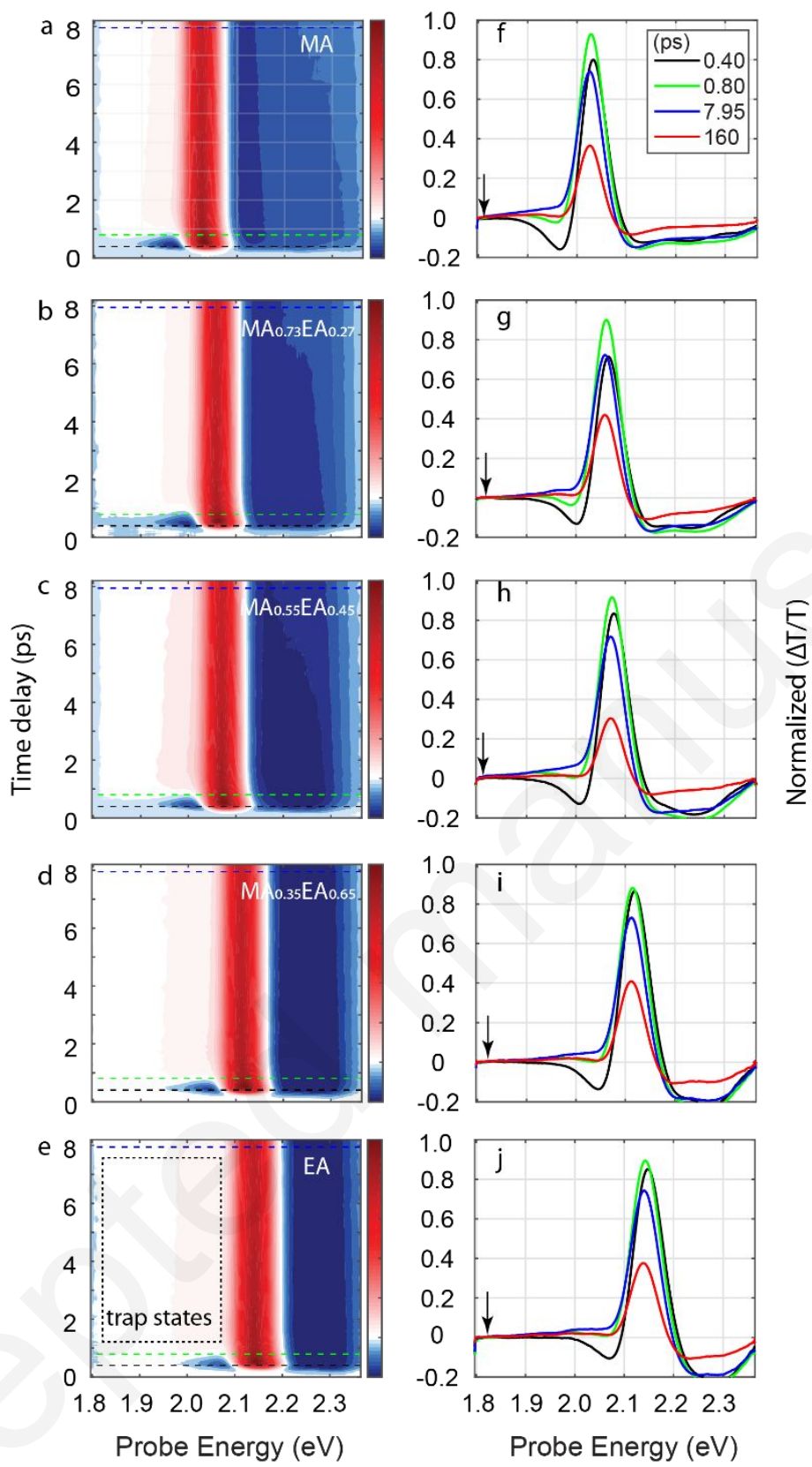

Figure 6. Pseudocolor plots of the normalized transient absorption (TA) spectra of the (a) MA, (b) $\mathrm{MA}_{0.73} \mathrm{EA}_{0.27}$, (c) $\mathrm{MA}_{0.55} \mathrm{EA}_{0.45}$, (d) $\mathrm{MA}_{0.35} \mathrm{EA}_{0.65}$, and (e) EA structures obtained with $2.41 \mathrm{eV}$ pump for the first 8 ps. Dash lines indicate the cuts at delay time of 0.40 ps (black), 0.80 ps (green), and 7.95 ps (black). TA spectra cuts of the (f) $\mathrm{MA}$, (g) $\mathrm{MA}_{0.73} \mathrm{EA}_{0.27}$, (h) $\mathrm{MA}_{0.55} \mathrm{EA}_{0.45}$, (i) 
$\mathrm{MA}_{0.35} \mathrm{EA}_{0.65}$, and (j) EA structures at four representative delay time points $(\mathrm{t}=0.40,0.80,7.95$, $160 \mathrm{ps})$. The arrows in f-g indicate the zero cross points of the curves at $7.95 \mathrm{ps}$.

The normalized dynamics of the four features in the pure MA and EA structures extracted at representative energy are plotted in Figure $7 \mathrm{a}$ and $7 \mathrm{~b}$. Convolution between different features exists because of unavoidable spectral overlap. To better decompose the highly convoluted TA spectra, spectra at late time delays ( $>160 \mathrm{ps})$ were acquired and a global analysis was performed on each TA spectra. Similar decay associated spectra (DAS) were generated from all five compositions (Figure S8). Only the ones from pure $(\mathrm{BA})_{2}(\mathrm{MA})_{2} \mathrm{~Pb}_{3} \mathrm{I}_{10}$ and $(\mathrm{BA})_{2}(\mathrm{EA})_{2} \mathrm{~Pb}_{3} \mathrm{I}_{10}$ are plotted here (Figure 7c and 7d). Three processes were gleaned from the global analysis. The pale green one shows a derivative shape and has a lifetime $<1 \mathrm{ps}$. The second component (blue, Figure 7c\&d) with picoseconds lifetime has a broad bleaching peak below the bandgap. The last component (black, Figure 7c\&d) comes with a relatively long lifetime and a bleaching at the bandgap. With the spectra and dynamics decomposed, we next discuss the assignment of the four features and analyze the dynamic processes. 

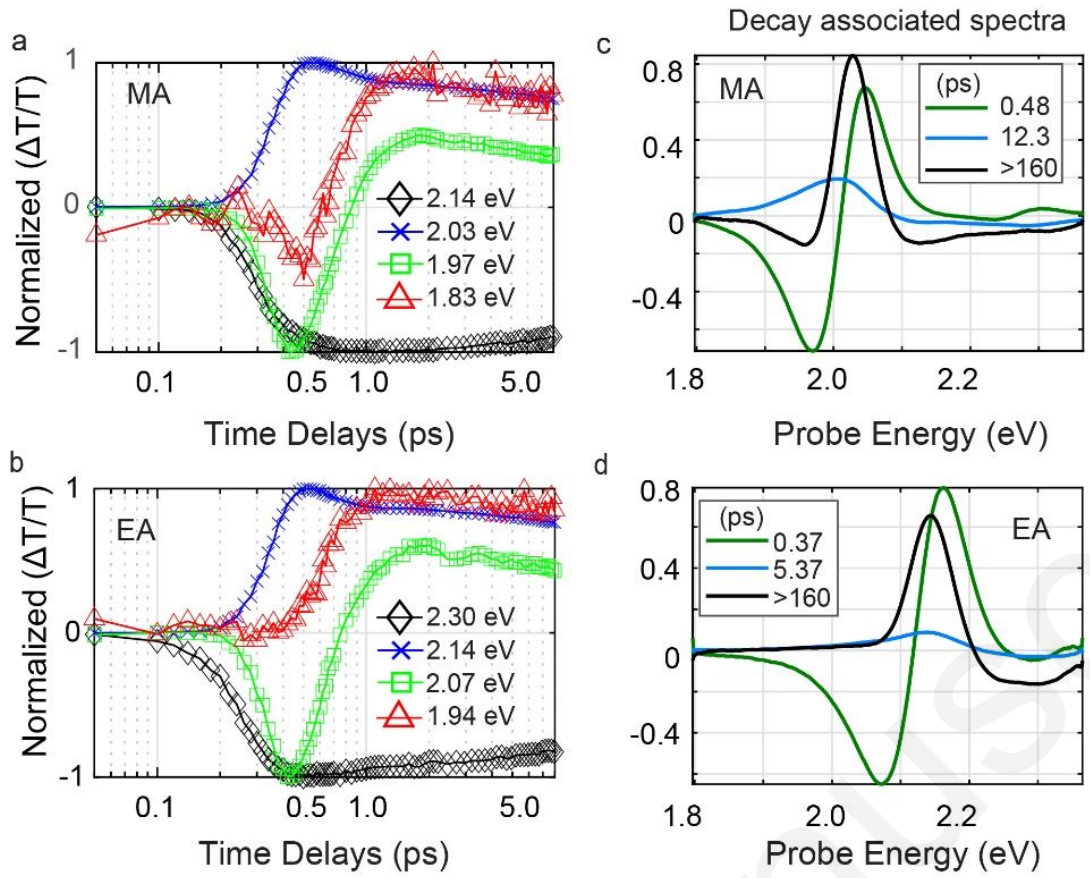

Figure 7. Normalized dynamics of bleaching below the bandgap (triangle), absorption below the bandgap (square), bleaching at the bandgap (cross), and absorption above the bandgap (diamond) of (a) $(\mathrm{BA})_{2}(\mathrm{MA})_{2} \mathrm{~Pb}_{3} \mathrm{I}_{10}$ and (b) $(\mathrm{BA})_{2}(\mathrm{EA})_{2} \mathrm{~Pb}_{3} \mathrm{I}_{10}$. Decay associated spectra of (c) $(\mathrm{BA})_{2}(\mathrm{MA})_{2} \mathrm{~Pb}_{3} \mathrm{I}_{10}$ and (b) $(\mathrm{BA})_{2}(\mathrm{EA})_{2} \mathrm{~Pb}_{3} \mathrm{I}_{10}$ obtained with global analysis.

The bandgap bleaching peak (blue, Figure $7 \mathrm{a}$ and $7 \mathrm{~b}$ ) with two main processes can be assigned to the band-edge population. The growing process likely comes from the fast bandgap bleaching and hot carrier relaxation, as its formation time aligns well with the lifetime of the first DAS, which will be discussed below. The decaying one has a relatively long lifetime and the spectra features overlap the last DAS, which presumably is associated with the recombination process usually lasting nanoseconds in perovskite materials. ${ }^{55}$ The short-lived ESA feature (green, squares), is most-likely to be associated with the shot-lived hot carriers. ${ }^{47,55-57}$ The fact that the absolute intensity of the peak decreased with an increasing bandgap value (as well as the $x$ value) 
is probably due to less excess energy of initial generated hot carriers. ${ }^{58}$ The first DAS, largely associated with this feature, may indicate the flow from higher energy levels to the bandgap. The long-lived ESA above the bandgap (black, diamonds) show no obvious decay before $8 \mathrm{ps,}$, and has similar dynamics to the main bleaching peak, as they both show up in the last DAS. We assign it to the ESA caused by band edge carrier, as higher band can be easily accessed according to the DFT calculation (Figure 5a and 5b). Another explanation could be that this peak is generated by the blue shift of the bandgap after excitation, however, we believe this likely to be less feasible as the amount of the blue shift did not change as a function of photo-excited carrier density or delay time (see details about the fluence-dependent study in Figure S9 and S10).

Though largely overlapping with the ESA, the bleaching below the bandgap (red, triangles) shows completely different growing dynamics compared to the main bleaching peak (blue, crosses). The energy of this sub-bandgap peak happens to overlap with the only peak in the second DAS. This indicates that this bleaching feature may be a separate process happening in the system other than hot-carrier cooling and bandgap renormalization summarized by the first and the last DAS. Judging by the peak location, it is most likely attributed to the trap states below the bandgap, as also suggested by other report. ${ }^{47}$ The lifetime of the second DAS is slightly longer than expected but still within the same scale of magnitude. This is probably because this peak convolves a lot with the main bleaching peak, and there is energy transfer back and forth between the two states.

As discussed above, the main electronic transitions of excited states are qualitatively similar in these structures. This can be understood by the fact that electronic band structures are mainly determined by the inorganic frameworks which are all made of $2 \mathrm{D}$ corner sharing $\mathrm{PbX}_{6}^{4-}$ octahedra. However, the change of octahedral parameters such as distortion level and $\mathrm{Pb}-\mathrm{I}$ bond length can modify the energy landscape, especially for the sub-bandgap states. As is shown in the 
Lastly, we discuss several possible explanations for the PL quenching. Worse crystals with more defects can lead to PL quenching. However, the clear trend of PL quenching cannot be simply attributed to the crystal quality, because all the crystals were synthesized in a similar condition. The single-crystal XRD data show that the EA structure has the best refinement (Table S1 and S2), indicating the crystal quality is at least comparable (if not better) to other structures. In contrast, the EA structure has the least PL emission. Therefore, the PL quenching might stem from the inherent structures with varied bonding characters.

Phonons that interact with charge carriers significantly impact non-radiative recombination rates. For example, a recent work established a correlation between the nonradiative recombination rate and molecular rigidity of spacer cations in 2D perovskites through exciton-phonon interaction. ${ }^{49}$ Charge carriers in perovskite materials are mainly coupled to the low-frequency vibrational modes of the Pb-I framework. One may expect that the elongated Pb-I bond length leads to softened phonon modes, which is especially assisted by the stereochemical activity of the $\mathrm{Pb}^{2+} 6 \mathrm{~s}^{2}$ lone pair of electrons. This process can induce more phonon mediated non-radiative recombination paths via exciton-phonon interaction. Indeed, the emission peak width is larger in the $(\mathrm{BA})_{2}(\mathrm{EA})_{2} \mathrm{~Pb}_{3} \mathrm{I}_{10}$ relative to $(\mathrm{BA})_{2}(\mathrm{MA})_{2} \mathrm{~Pb}_{3} \mathrm{I}_{10}$, indicating a stronger exciton phonon interaction in the former.

A second explanation is that, the $\mathrm{Pb}-\mathrm{I}$ bond strength may influence the thermodynamics of interstitial iodine defects which could introduce deep energy levels within the bandgap. A recent 
proposal suggested the key to explaining the so-called defect tolerance in perovskites lays in the photochemical properties of such defects. ${ }^{59}$ Such defects acting as recombination centers can accelerate non-radiative recombination of charge carriers and thus reduce the photoluminescence. Our transient absorption measurements reveal the existence of the trap states by applying global analysis and separate the energy transferring processes related to this state. The broader energetic distribution of the trap states correlates well to the PL quenching, while the radiative emission from these trap states may lead to the asymmetric PL peak in the higher EA content structures.

\section{CONCLUSIONS}

The Goldschmidt rule of perovskite cage stability is significantly relaxed with EA as the cage cation. This cation is larger than the rule allows yet it incorporates in the perovskite cage by stretching it, giving rise to a stretched version of the $n=32 \mathrm{D}$ perovskite structure featuring the longest $\mathrm{Pb}-\mathrm{I}$ bond lengths and extremely large octahedral distortion. In contrast to the bandgap redshift in $3 \mathrm{D} \mathrm{APbI}_{3}$ with increasing the cation size, the alloyed 2D perovskites exhibit blue-shifted bandgap with increasing EA content (equivalent to increasing the size of A-cation). The bandgap blueshift is consistent with the band structure calculations and can be explained by the significant volumetric expansion of the perovskite cage with increased $\mathrm{Pb}$-I bond length. Moreover, it is found that the structure with larger octahedral distortion and longer Pb-I bond length has stronger PL quenching and more asymmetric PL peak. Transient absorption spectroscopy measurements reveal similar excited state dynamics and the existence of a broad distribution of trap states below the bandgap. The energetic distribution of trap states is broader with lager octahedral distortion and/or longer $\mathrm{Pb}$-I bond length, which might be responsible for the asymmetricity and quenching of the 


\begin{abstract}
PL emission. Our results provide guidelines for rational design of new and more efficient perovskite materials for optoelectronic applications.
\end{abstract}

\title{
EXPERIMENTAL SECTION
}

All chemicals and regents were purchased from Sigma-Aldrich and used as received unless noted otherwise.

Growth of $(\mathrm{BA})_{2}\left(\mathrm{EA}_{x} \mathrm{MA}_{1-x}\right)_{2} \mathrm{~Pb}_{3} \mathrm{I}_{10}$ single crystals and ${ }^{1} \mathrm{H}$ NMR measurements. The crystals were grown from concentrated hydroiodic acid using previously reported offstoichiometry protocol. ${ }^{44,60}$ Specifically, to grow $(\mathrm{BA})_{2}(\mathrm{EA})_{2} \mathrm{~Pb}_{3} \mathrm{I}_{10}$ single crystals, powders of $\mathrm{PbI}_{2}$ (1380 mg), EAI (346 mg), and BAI (175 mg) were dissolved in $4.5 \mathrm{~mL}$ of HI solution (57 wt $\%$ in $\mathrm{H}_{2} \mathrm{O}$ ) and $0.5 \mathrm{~mL}$ of $\mathrm{H}_{3} \mathrm{PO}_{2}$ in a vial. Note that the solution was heated to $120{ }^{\circ} \mathrm{C}$ on a hot plate to completely dissolve all the solids. The solution was kept on a hot plate until $\sim 1 / 3$ of the solution had evaporated. Red rectangular plate-like crystals precipitated during cooling to room temperature. To grow $(\mathrm{BA})_{2}(\mathrm{MA})_{2} \mathrm{~Pb}_{3} \mathrm{I}_{10}$ single crystals, powders of $\mathrm{PbI}_{2}(1380 \mathrm{mg})$, MAI (318 $\mathrm{mg}$ ), and BAI (175 mg) were dissolved in $4.5 \mathrm{~mL}$ of $\mathrm{HI}$ solution $\left(57 \mathrm{wt} \%\right.$ in $\left.\mathrm{H}_{2} \mathrm{O}\right)$ and $0.5 \mathrm{~mL}$ of $\mathrm{H}_{3} \mathrm{PO}_{2}$ in a vial. The solution was heated to $120{ }^{\circ} \mathrm{C}$ on a hot plate to completely dissolve all the solids. The solution sited undisturbed at room temperature for several hours to yield red-black flake-like single crystals. Similar, the precursor solutions for $(\mathrm{BA})_{2}(\mathrm{EA})_{2} \mathrm{~Pb}_{3} \mathrm{I}_{10}$ and $(\mathrm{BA})_{2}(\mathrm{MA})_{2} \mathrm{~Pb}_{3} \mathrm{I}_{10}$ were mixed at volumetric ratios of 1:2, 1:1, and 2:1 to grow mixed cation alloys. ${ }^{1} \mathrm{H}-\mathrm{NMR}$ spectra were measured on the dissolved crystals with Bruker Avance III $600 \mathrm{MHz}$ system with BBI probe. 
Exfoliated crystal preparation. Samples for the TAM measurements were prepared by mechanical exfoliation. Plate-like single crystals were picked and were put on a clear scotch onesided tape, on top of which another clean area of the tape was folded. Parts of the crystals were detached from the crystals for further exfoliation, exposing fresh cleaved layers, and the rest of the crystals remained on the tape. This process was repeated for several times to obtain optically thin 2D perovskite sheets (see Figure S11 for an optical image). The exfoliated crystals were then transferred on to a piece of coverslip by pressing the tape on top of the coverslip. After that, a protective layer of poly (methyl methacrylate) (Mw 120000 by GPC, PMMA) was deposited on the coverslip by spin-coating a solution containing $4 \mathrm{wt} \%$ PMMA in chlorobenzene at $3000 \mathrm{rpm}$ for $30 \mathrm{~s}$. The samples were sealed by another coverslip using parafilm as a spacer on a hot plate $\left(100^{\circ} \mathrm{C}\right)$ in the ambient air.

Single crystal structure determination. Single-crystal X-ray diffraction experiments were performed using a STOE IPDS II or IPDS 2T diffractometer with Mo K $\alpha$ radiation $(\lambda=0.71073$ $\AA$ ) and operating at $50 \mathrm{kV}$ and $40 \mathrm{~mA}$. Integration and numerical absorption corrections were performed using the X-AREA, X-RED, and X-SHAPE programs. The structures were solved by charge flipping and refined by full-matrix least-squares on $\mathrm{F}^{2}$ using the Jana 2006 package.

Photoluminescence spectrum. Steady-state PL spectra of single crystals were collected using HORIBA LabRAM HR Evolution confocal Raman microscope with $532 \mathrm{~nm}$ laser excitation. The crystals were exfoliated by scotch tape once to expose fresh surface, and same excitation power density was used for all the measurements.

DFT calculations. The calculations were performed within the Density Functional Theory $(D F T)^{61,62}$ as implemented in SIESTA package ${ }^{63}$ with a basis set of finite-range of numerical atomic orbitals. We used the Generalized Gradient Approximation (GGA) with Perdew-Burke- 
Ernzerhof (PBE) functional to describe the exchange-correlation term, and norm-conserving Troullier-Martins pseudopotentials were used for each atomic species to account for the core electrons. ${ }^{64} 1 \mathrm{~s}^{1}, 2 \mathrm{~s}^{2} 2 \mathrm{p}^{2}, 2 \mathrm{~s}^{2} 2 \mathrm{p}^{3}, 5 \mathrm{~s}^{2} 5 \mathrm{p}^{5}$ and $5 \mathrm{~d}^{10} 6 \mathrm{~s}^{2} 6 \mathrm{p}^{2}$ were used as valence electrons for $\mathrm{H}, \mathrm{C}, \mathrm{N}$, $\mathrm{I}$, and $\mathrm{Pb}$ respectively. Polarized Double-Zeta (DZP) basis set with an energy shift of $50 \mathrm{meV}$ and a Mesh cutoff 200 Rydberg were used for the calculations. The Brillouin zone was sampled with $2 \times 2 \times 6$ and $4 \times 4 \times 1$ Monckhorst-Pack grids for the primitive cells and slab systems, respectively. The electronic and dielectric properties were calculated with the experimental lattice parameters, and atomic coordinates were transformed to their primitive cells whenever applicable. Spin-orbit coupling (SOC) was taken into account in the calculation of the electronic properties, although it was not considered in the high-frequency dielectric constant computations. For the high-frequency dielectric constant profiles, the (010) surface of $(\mathrm{BA})_{2}(\mathrm{MA})_{2} \mathrm{~Pb}_{3} \mathrm{I}_{10}$ was considered. For technical reasons, the surface was rotated such that the stacking corresponds to the z-axis. Slabs based on the respective systems were constructed and an electric field of $0.01 \mathrm{eV} / \AA$ was applied along the [001] direction with the relaxation of the sole electron density as described elsewhere. 65,66

Additional TB-mBJ calculations along with the computation of the electric dipole matrix elements were done with the ABINIT code. ${ }^{67}$ The electric dipole matrix elements were computed as in the reference ${ }^{53}$ with the LDA exchange-correlation functional ${ }^{68}$ used for the description of the spinor wave functions. The relativistic, norm conserving, separable, dual-space Gaussian-type pseudopotentials of Hartwigsen, Goedecker, and Hutter were used for all atoms. ${ }^{69}$ More specifically, we considered $6 \mathrm{~s}^{1}, 5 \mathrm{~s}^{2} 5 \mathrm{p}^{2}$ and $6 \mathrm{~s}^{2} 6 \mathrm{p}^{2}$ as valence electrons for $\mathrm{Cs} \mathrm{I}$, and $\mathrm{Pb}$, respectively. TB-mBJ in ABINIT was invoked from the library of exchange-correlation functionals Libxc. ${ }^{70}$ We used optimized pseudopotential TB-mBJ (ppTB-mBJ) parameters $\alpha=$ 
0.65 and $\beta=1.023$ for hybrid perovskites within pseudopotential implementation of DFT as detailed elsewhere. ${ }^{51}$ All the calculations take SOC into account.

Transient absorption microscopy. The block diagram of the home-built TAM is shown in Figure S12 and our previous paper. ${ }^{71}$ Briefly, the fundamental $1030-\mathrm{nm}$ beam was generated from an Yb:KGW amplifier system (Light Conversion, PHAROS) operating at $200 \mathrm{kHz}$ with a pulse duration of 190 fs. The beam was split into pump and probe arms. The pump was focused into a beta barium borate $(\mathrm{BBO})$ crystal to produce second harmonic generation light centered at $515 \mathrm{~nm}$. The pump was then delayed relative to the probe with a high resolution motorized linear stage (Aerotech). White-light probe $(1.74-2.28 \mathrm{eV})$ was generated by focusing the fundamental beam into an yttrium aluminum garnet (YAG) crystal and then compressed with a pair of chirped mirrors (DCM, LayerTec). Both beams were recombined and focused collinearly onto the sample with a $74 \times$ reflective objective (NA 0.65 , Beck). The beam spot size was $\sim 0.6 \mu \mathrm{m}$. The sample was taped on a piezo-driven XYZ stage with a resolution of $0.2 \mu \mathrm{m}$ (PiezosystemJena, Newport XPS). The signal was collected using a $100 \times$ refractive objective (NA 0.70, Leica), spatially filtered through a 300- $\mu \mathrm{m}$ pinhole, and then spectrally dispersed in a spectrometer (Horiba, IHR-320). The TA signal was detected using a high-speed CCD camera (Andor, Ixon Ultra 897). Linear absorption of probe and photoluminescence (PL) maps were measured within the same setup. The results shown in the main text are the average of about 10-15 exfoliated flakes on each sample at an excitation power of $450 \mathrm{nW}$. The decay associated spectra (DAS) was obtained by globally fit the entire TA dataset. Multiple-exponential fit was performed at each wavelength to extract the lifetimes of the DASs. The fitting algorithm used was the "fminuit" package in MATLAB. A "seek" step was added to avoid convergence at the local minimum. 


\section{ASSOCIATED CONTENT}

\section{Supporting Information}

Supplementary discussion on the difference of localization of electronic densities between $(\mathrm{BA})_{2}(\mathrm{MA})_{2} \mathrm{~Pb}_{3} \mathrm{I}_{10}$ and $(\mathrm{BA})_{2}(\mathrm{EA})_{2} \mathrm{~Pb}_{3} \mathrm{I}_{10}$ at $\mathrm{VBM}$ and $\mathrm{CBM}$, crystal and structure refinement data of $(\mathrm{BA})_{2}\left(\mathrm{EA}_{x} \mathrm{MA}_{1-x}\right)_{2} \mathrm{~Pb}_{3} \mathrm{I}_{10}(x=0,0.27,0.45,0.67,1)$, comparison of structural parameters and optical bandgap for various $2 \mathrm{D}$ lead iodide perovskites with $n=3$, comparison of optical bandgap and structural parameters for the $3 \mathrm{D}$ lead iodide perovskites $\mathrm{APbI}_{3}$, comparison of the effective masses between $(\mathrm{BA})_{2}(\mathrm{MA})_{2} \mathrm{~Pb}_{3} \mathrm{I}_{10}$ and $(\mathrm{BA})_{2}(\mathrm{EA})_{2} \mathrm{~Pb}_{3} \mathrm{I}_{10}$, photographs of the set of $(\mathrm{BA})_{2}\left(\mathrm{EA}_{x} \mathrm{MA}_{1-x}\right)_{2} \mathrm{~Pb}_{3} \mathrm{I}_{10}$, computed dielectric profiles of $(\mathrm{BA})_{2}(\mathrm{MA})_{2} \mathrm{~Pb}_{3} \mathrm{I}_{10}$ and $(\mathrm{BA})_{2}(\mathrm{EA})_{2} \mathrm{~Pb}_{3} \mathrm{I}_{10}$, power-dependent TA studies, decay associated spectra of $(\mathrm{BA})_{2}\left(\mathrm{EA}_{x} \mathrm{MA}_{1-}\right.$ $\left.{ }_{x}\right)_{2} \mathrm{~Pb}_{3} \mathrm{I}_{10}$, optical image of exfoliated crystals, cif files of $(\mathrm{BA})_{2}\left(\mathrm{EA}_{x} \mathrm{MA}_{1-x}\right)_{2} \mathrm{~Pb}_{3} \mathrm{I}_{10}(x=0.27,0.45$, $0.67,1)$. This material is available free of charge via the Internet at http://pubs.acs.org.

\section{AUTHOR INFORMATION \\ Corresponding Author \\ *E-mail: $\underline{\text { m-kanatzidis@,northwestern.edu, elharel@msu.edu }}$}

\section{Notes}

The authors declare no competing financial interest.

\section{ACKNOWLEDGMENT}

The structural characterization work was supported by the Office of Naval Research, under Grant N00014-17-1-2231 (X.L and M.G.K.). The calculation work was granted access to the HPC 
resources of [TGCC/INES/IDRIS] under the allocations 2019 A0010907682 made by GENCI. J.E. acknowledges financial support from the Institut Universitaire de France. This work made use of the EPIC facility of Northwestern University's NUANCE Center, which has received support from the Soft and Hybrid Nanotechnology Experimental (SHyNE) Resource (NSF ECCS-1542205); the MRSEC program (NSF DMR-1720139) at the Materials Research Center; the International Institute for Nanotechnology (IIN); the Keck Foundation; and the State of Illinois, through the IIN. Funding for this research was provided by the Enabling Quantum Leap program; an NSF EAGER grant under award number DMR-1838507.

\section{REFERENCES}

(1) Lee, M. M.; Teuscher, J.; Miyasaka, T.; Murakami, T. N.; Snaith, H. J. Efficient Hybrid Solar Cells Based on Meso-Superstructured Organometal Halide Perovskites. Science 2012, 338, 643.

(2) Fu, Y.; Zhu, H.; Chen, J.; Hautzinger, M. P.; Zhu, X. Y.; Jin, S. Metal halide perovskite nanostructures for optoelectronic applications and the study of physical properties. Nature Reviews Materials 2019, 4, 169.

(3) Chung, I.; Lee, B.; He, J.; Chang, R. P. H.; Kanatzidis, M. G. All-solid-state dyesensitized solar cells with high efficiency. Nature 2012, 485, 486.

(4) Kojima, A.; Teshima, K.; Shirai, Y.; Miyasaka, T. Organometal halide perovskites as visible-light sensitizers for photovoltaic cells. 2009, 131, 6050.

(5) Mao, L.; Stoumpos, C. C.; Kanatzidis, M. G. Two-Dimensional Hybrid Halide Perovskites: Principles and Promises. 2019, 141,

1171.

(6) Katan, C.; Mercier, N.; Even, J. Quantum and Dielectric Confinement Effects in LowerDimensional Hybrid Perovskite Semiconductors. Chemical Reviews 2019, 119, 3140.

(7) Leveillee, J.; Katan, C.; Even, J.; Ghosh, D.; Nie, W.; Mohite, A. D.; Tretiak, S.; Schleife, A.; Neukirch, A. J. Tuning Electronic Structure in Layered Hybrid Perovskites with Organic Spacer Substitution. Nano Letters 2019, 19, 8732.

(8) Saparov, B.; Mitzi, D. B. Organic-Inorganic Perovskites: Structural Versatility for Functional Materials Design. Chemical Reviews 2016, 116, 4558.

(9) Gao, Y.; Shi, E.; Deng, S.; Shiring, S. B.; Snaider, J. M.; Liang, C.; Yuan, B.; Song, R.; Janke, S. M.; Liebman-Peláez, A.; Yoo, P.; Zeller, M.; Boudouris, B. W.; Liao, P.; Zhu, C.; Blum, V.; Yu, Y.; Savoie, B. M.; Huang, L.; Dou, L. Molecular engineering of organicinorganic hybrid perovskites quantum wells. Nature Chemistry 2019, 11, 1151. 
(10) Gao, Y.; Wei, Z.; Yoo, P.; Shi, E.; Zeller, M.; Zhu, C.; Liao, P.; Dou, L. Highly Stable Lead-Free Perovskite Field-Effect Transistors Incorporating Linear $\pi$-Conjugated Organic Ligands. 2019, 141, 15577.

(11) Fu, Y.; Zheng, W.; Wang, X.; Hautzinger, M. P.; Pan, D.; Dang, L.; Wright, J. C.; Pan, A.; Jin, S. Multicolor Heterostructures of Two-Dimensional Layered Halide Perovskites that Show Interlayer Energy Transfer. 2018, 140, 15675.(12) Traore, B.; Pedesseau, L.; Assam, L.; Che, X.; Blancon, J.-C.; Tsai, H.; Nie, W.; Stoumpos, C. C.; Kanatzidis, M. G.; Tretiak, S.; Mohite, A. D.; Even, J.; Kepenekian, M.; Katan, C. Composite Nature of Layered Hybrid Perovskites: Assessment on Quantum and Dielectric Confinements and Band Alignment. ACS Nano 2018, 12, 3321.

(13) Ishihara, T.; Takahashi, J.; Goto, T. Exciton state in two-dimensional perovskite semiconductor $\left(\mathrm{C}_{10} \mathrm{H}_{21} \mathrm{NH}_{3}\right)_{2} \mathrm{PbI}_{4}$. Solid State Communications 1989, 69, 933.

(14) Xu, C.-q.; Kondo, T.; Sakakura, H.; Kumata, K.; Takahashi, Y.; Ito, R. Optical thirdharmonic generation in layered perovskite-type material $\left(\mathrm{C}_{10} \mathrm{H}_{21} \mathrm{NH}_{3}\right)_{2} \mathrm{PbI}_{4}$. Solid State Communications 1991, 79, 245.

(15) Stoumpos, C. C.; Mao, L.; Malliakas, C. D.; Kanatzidis, M. G. Structure-Band Gap Relationships in Hexagonal Polytypes and Low-Dimensional Structures of Hybrid Tin Iodide Perovskites. Inorganic Chemistry 2017, 56, 56.

(16) Knutson, J. L.; Martin, J. D.; Mitzi, D. B. Tuning the Band Gap in Hybrid Tin Iodide Perovskite Semiconductors Using Structural Templating. Inorganic Chemistry 2005, 44, 4699.

(17) Stoumpos, C. C.; Kanatzidis, M. G. The Renaissance of Halide Perovskites and Their Evolution as Emerging Semiconductors. Accounts of Chemical Research 2015, 48, 2791.

(18) Miyata, K.; Atallah, T. L.; Zhu, X.-Y. Lead halide perovskites: Crystal-liquid duality, phonon glass electron crystals, and large polaron formation. Science Advances 2017, 3.

(19) Zhu, H.; Wyata, K.; Fu, Y.; Wang, J.; Joshi, P. P.; Niesner, D.; Williams, K. W.; Jin, S.; Zhu, X.-Y. Screening in crystalline liquids protects energetic carriers in hybrid perovskites.

Science 2016, 353, 1409.

(20) Hutter, E. M.; Gélvez-Rueda, M. C.; Osherov, A.; Bulović, V.; Grozema, F. C.; Stranks, S. D.; Savenije, T. J. Direct-indirect character of the bandgap in methylammonium lead iodide perovskite. Nature Materials 2016, 16, 115.

(21) Zhu, H.; Trinh, M. T.; Wang, J.; Fu, Y.; Joshi, P. P.; Miyata, K.; Jin, S.; Zhu, X. Y.

Lead Halide Perovskites. Advanced Materials 2017, 1603072.

(22) Guo, Y.; Yaffe, O.; Paley, D. W.; Beecher, A. N.; Hull, T. D.; Szpak, G.; Owen, J. S.; Brus, L. E.; Pimenta, M. A. Interplay between organic cations and inorganic framework and incommensurability in hybrid lead-halide perovskite $\mathrm{CH}_{3} \mathrm{NH}_{3} \mathrm{PbBr}_{3}$. Physical Review Materials 2017, 1, 042401.

(23) Egger, D. A.; Bera, A.; Cahen, D.; Hodes, G.; Kirchartz, T.; Kronik, L.; Lovrincic, R.; Rappe, A. M.; Reichman, D. R.; Yaffe, O. What Remains Unexplained about the Properties of Halide Perorstites?Advanced Materials 2018, 30, 1800691.

24CGon, Mohite, A. D.; Even, J. Entropy in halide perovskites. Nature Materials 2018, 17, 377.

(25) Miyata, K.; Zhu, X. Y. Ferroelectric large polarons. Nature Materials 2018, 17, 379.

(26) Stranks, S. D.; Plochocka, P. The influence of the Rashba effect. Nature Materials 2018, 17,381 . 
(27) Kieslich, G.; Sun, S.; Cheetham, A. K. Solid-state principles applied to organic-inorganic perovskites: new tricks for an old dog. Chemical Science 2014, 5, 4712.

(28) Travis, W.; Glover, E. N. K.; Bronstein, H.; Scanlon, D. O.; Palgrave, R. G. On the application of the tolerance factor to inorganic and hybrid halide perovskites: a revised system. Chemical Science 2016, 7, 4548.

(29) Fu, Y.; Wu, T.; Wang, J.; Zhai, J.; Shearer, M. J.; Zhao, Y.; Hamers, R. J.; Kan, E.; Deng, K.; Zhu, X. Y.; Jin, S. Stabilization of the Metastable Lead Iodide Perovskite Phase via Surface Functionalization. Nano Letters 2017, 17, 4405.

(30) Ke, W.; Spanopoulos, I.; Stoumpos, C. C.; Kanatzidis, M. G. Myths and reality of $\mathrm{HPbI}_{3}$ in halide perovskite solar cells. Nature Communications 2018, 9, 4785.

(31) Jodlowski, A. D.; Roldán-Carmona, C.; Grancini, G.; Salado, M.; Ralaiarisoa, M.; Ahmad, S.; Koch, N.; Camacho, L.; de Miguel, G.; Nazeeruddin, M. K. Large guanidinium cation mixed with methylammonium in lead iodide perovskites for $19 \%$ efficient solar cells. Nature Energy 2017, 2, 972.

(32) Peng, W.; Miao, X.; Adinolfi, V.; Alarousu, E.; El Tall, O.; Emwas, A.-H.; Zhao, C.; Walters, G.; Liu, J.; Ouellette, O.; Pan, J.; Murali, B.; Sargent, E. H.; Mohammed, O. F.; Bakr, O. M. Engineering of $\mathrm{CH}_{3} \mathrm{NH}_{3} \mathrm{PbI}_{3}$ Perovskite Crystals by Alloying Large Organic Cations for Enhanced Thermal Stability and Transport Properties. Angewandte Chemie International Edition 2016, 55, 10686.

(33) Ke, W.; Stoumpos, C. C.; Zhu, M.; Mao, L.; Spanopoulos, I.; Liu, J.; Kontsevoi, O. Y.; Chen, M.; Sarma, D.; Zhang, Y.; Wasielewski, M. R.; Kanatzidis, M. G. Enhanced photovoltaic performance and stability with a new type of hollow 3D perovskite $\{\mathrm{en}\} \mathrm{FASnI}_{3}$. Science Advances 2017, 3, e1701293.

(34) Spanopoulos, I.; Ke, W.; Stoumpos, C. C.; Schueller, E. C.; Kontsevoi, O. Y.; Seshadri, R.; Kanatzidis, M. SUnraveling the Chemical Nature of the 3D "Hollow" Hybrid Halide Perovskites. 2018, I40, 5728.

(35) Leblanc, A.; Mercier, N.; Allain, M.; Dittmer, J.; Pauporté, T.; Fernandez, V.; Boucher,

F.; Kepenekian, M.; Katan, C. Enhanced Stability and Band Gap Tuning of $\alpha-\left[\mathrm{HC}\left(\mathrm{NH}_{2}\right)_{2}\right] \mathrm{PbI}_{3}$ 2074rid Perovskite by Large Cation Integration. ACS Applied Materials \& Interfaces 2019, 11, (36) Passarelli, J. V.; Fairfield, D. J.; Sather, N. A.; Hendricks, M. P.; Sai, H.; Stern, C. L.; Stupp, S. I. Enhanced Out-of-Plane Conductivity and Photovoltaic Performance in $n=1$ Layered Perovskites through Organic Cation Design. 2018, 140, 7313.

(37) Fu, Y.; Hautzinger, M. P.; Luo, Z.; Wang, F.; Pan, D.; Aristov, M. M.; Guzei, I. A.; Pan, A.; Zhu, X.; Jin, S. Incorporating Large A Cations into Lead Iodide Perovskite Cages: Relaxed Goldschmidt Tolerance Factor and Impact on Exciton-Phonon Interaction. ACS Central Science 2019, 5, 1377.

(38) Xu, Z.; Li, Y.; Liu, X.; Ji, C.; Chen, H.; Li, L.; Han, S.; Hong, M.; Luo, J.; Sun, Z. Highly Sensitive and Ultrafast Responding Array Photodetector Based on a Newly Tailored 2D Lead Iodide Perovskite Crystal. Advanced Optical Materials 2019, 7, 1900308.

(3) Mao, L.; Wu, Y.; Stoumpos, C. C.; Traore, B.; Katan, C.; Even, J.; Wasielewski, M. R.; Kanatzidis, M. G. Tunable White-Light Emission in Single-Cation-Templated Three-Layered 2D Perovskites $\left(\mathrm{CH}_{3} \mathrm{CH}_{2} \mathrm{NH}_{3}\right)_{4} \mathrm{~Pb}_{3} \mathrm{Br}_{10-\mathrm{x}} \mathrm{Cl}_{\mathrm{x}}$. 2017, 139,

11956. 

decachlorotriplumbate(II), $\left(\mathrm{C}_{2} \mathrm{H}_{5} \mathrm{NH}_{3}\right)_{4} \mathrm{~Pb}_{3} \mathrm{Cl}_{10}$. Zeitschrift für Kristallographie - New Crystal Structures 1997, 212, 241.

(41) Wang, S.; Liu, X.; Li, L.; Ji, C.; Sun, Z.; Wu, Z.; Hong, M.; Luo, J. An Unprecedented Biaxial Trilayered Hybrid Perovskite Ferroelectric with Directionally Tunable Photovoltaic Effects. 2019, 141, 7693.

(42) Stoumpos, C. C.; Malliakas, C. D.; Kanatzidis, M. G. Semiconducting Tin and Lead Iodide Perovskites with Organic Cations: Phase Transitions, High Mobilities, and Near-Infrared Photoluminescent Properties. Inorganic Chemistry 2013, 52, 9019.

(43) Dai, J.; Fu, Y.; Manger, L. H.; Rea, M. T.; Hwang, L.; Goldsmith, R. H.; Jin, S. Carrier Decay Properties of Mixed Cation Formamidinium-Methylammonium Lead Iodide Perovskite $\left[\mathrm{HC}\left(\mathrm{NH}_{2}\right)_{2}\right]_{1-\mathrm{x}}\left[\mathrm{CH}_{3} \mathrm{NH}_{3}\right]_{\mathrm{x}} \mathrm{PbI}_{3}$ Nanorods. The Journal of Physical Chemistry Letters 2016, 7 , 5036.

(44) Stoumpos, C. C.; Cao, D. H.; Clark, D. J.; Young, J.; Rondinelli, J. M.; Jang, J. I.; Hupp, J. T.; Kanatzidis, M. G. Ruddlesden-Popper Hybrid Lead Iodide Perovskite 2D Homologous Semiconductors. Chemistry of Materials 2016, 28, 2852.

(45) Du, K.-z.; Tu, Q.; Zhang, X.; Han, Q.; Liu, J.; Zauscher, S.; Mitzi, D. B. TwoDimensional Lead(II) Halide-Based Hybrid Perovskites Templated by Acene Alkylamines: Crystal Structures, Optical Properties, and Piezoelectricity. Inorganic Chemistry 2017, 56, 9291. (46) Kepenekian, M.; Traore, B.; Blancon, J.-C.; Pedesseau, L.; Tsai, H.; Nie, W.; Stoumpos, C. C.; Kanatzidis, M. G.; Even, J.; Mohite, A. D.; Tretiak, S.; Katan, C. Concept of Lattice Mismatch and Emergence of Surface States in Two-dimensional Hybrid Perovskite Quantum Wells. Nano Letters 2018, 18, 5603.

(47) Wu, X.; Trinh, M. T.; Zhu, X. Y. Excitonic Many-Body Interactions in Two-Dimensional Lead Iodide Perovskite Quantum Wells. The Journal of Physical Chemistry C 2015, 119, 14714.

(48) Liu, G.; Gong, J.; Kong, L.; Schaller, R. D.; Hu, Q.; Liu, Z.; Yan, S.; Yang, W.; Stoumpos, C. C.; Kanatzidis, M. G.; Mao, H.-k.; Xu, T. Isothermal pressure-derived metastable states in 2D hybrid perovskites showing enduring bandgap narrowing. Proceedings of the National Academy of Sciences 2018, 115, 8076.

(49) Gong, X.; Voznyy, O.; Jain, A.; Liu, W.; Sabatini, R.; Piontkowski, Z.; Walters, G.; Bappi, G.; Nokhrin, S.; Bushuyev, O.; Yuan, M.; Comin, R.; McCamant, D.; Kelley, S. O.; Sargent, E. H. Electron-phonon interaction in efficient perovskite blue emitters. Nature Materials 2018, 17, 550.

(50) Pedesseau, L.; Sapori, D.; Traore, B.; Robles, R.; Fang, H.-H.; Loi, M. A.; Tsai, H.; Nie, W.; Blancon, J.-C.; Neukirch, A.; Tretiak, S.; Mohite, A. D.; Katan, C.; Even, J.; Kepenekian, M. Advances and Promises of Layered Halide Hybrid Perovskite Semiconductors. ACS Nano 2016, $10,9776$.

(51) Traoré, B.; Bouder, G.; Lafargue-Dit-Hauret, W.; Rocquefelte, X.; Katan, C.; Tran, F.; Kepenekian, M. Efficient and accurate calculation of band gaps of halide perovskites with the Tran-Blaha modified Becke-Johnson potential. Physical Review B 2019, 99, 035139.

(52) Blancon, J. C.; Stier, A. V.; Tsai, H.; Nie, W.; Stoumpos, C. C.; Traoré, B.; Pedesseau, L.; Kepenekian, M.; Katsutani, F.; Noe, G. T.; Kono, J.; Tretiak, S.; Crooker, S. A.; Katan, C.; Kanatzidis, M. G.; Crochet, J. J.; Even, J.; Mohite, A. D. Scaling law for excitons in 2D perovskite quantum wells. Nature Communications 2018, 9, 2254. 
(53) Even, J.; Pedesseau, L.; Dupertuis, M. A.; Jancu, J. M.; Katan, C. Electronic model for self-assembled hybrid organic/perovskite semiconductors: Reverse band edge electronic states ordering and spin-orbit coupling. Physical Review B 2012, 86, 205301.

(54) Even, J.; Pedesseau, L.; Katan, C. Understanding Quantum Confinement of Charge Carriers in Layered 2D Hybrid Perovskites. ChemPhysChem 2014, 15, 3733.

(55) Yang, Y.; Ostrowski, D. P.; France, R. M.; Zhu, K.; van de Lagemaat, J.; Luther, J. M.; Beard, M. C. Observation of a hot-phonon bottleneck in lead-iodide perovskites. Nature Photonics 2015, 10, 53.

(56) Mondal, A.; Aneesh, J.; Kumar Ravi, V.; Sharma, R.; Mir, W. J.; Beard, M. C.; Nag, A.; Adarsh, K. V. Ultrafast exciton many-body interactions and hot-phonon bottleneck in colloidal cesium lead halide perovskite nanocrystals. Physical Review B 2018, 98, 115418.

(57) Nah, S.; Spokoyny, B.; Stoumpos, C.; Soe, C. M. M.; Kanatzidis, M.; Harel, E. Spatially segregated free-carrier and exciton populations in individual lead halide perovskite grains.

Nature Photonics 2017, 11, 285.

(58) Mondal, A.; Aneesh, J.; Ravi, V. K.; Sharma, R.; Mir, W. J.; Beard, M. C.; Nag, A.; Adarsh, K. V. Ultrafast exciton many-body interactions and hot-phonon bottleneck in colloidal cesium lead halide perovskite nanocrystals. Physical Review B 2018, 98.

(59) De Angelis, F.; Petrozza, A. Clues from defect photochemistry. Nature Materials 2018, 17,383 .

(60) Leng, K.; Abdelwahab, I.; Verzhbitskiy, I.; Telychko, M.; Chu, L.; Fu, W.; Chi, X.; Guo, N.; Chen, Z.; Chen, Z.; Zhang, C.; Xu, Q.-H.; Lu, J.; Chhowalla, M.; Eda, G.; Loh, K. P.

Molecularly thin two-dimensional hybrid perovskites with tunable optoelectronic properties due to reversible surface relaxation. Nature Materials 2018, 17, 908.

(61) Hohenberg, P.; Kohn, W. Inhomogeneous Electron Gas. Physical Review 1964, 136, B864.

(62) Kohn, W.; Sham, L. J. Self-Consistent Equations Including Exchange and Correlation Effects. Physical Review 1965, 140, A1133.

(63) Soler, J. M.; Artacho, E.; Gale, J. D.; García, A.; Junquera, J.; Ordejón, P.; SánchezPortal, D. The SIESTA method forab initioorder-Nmaterials simulation. Journal of Physics: Condensed Matter 2002, 14, 2745.

(64) Troullier, N.; Martins, J. L. Efficient pseudopotentials for plane-wave calculations. Physical Review B 1991, 43, 1993.

(65) Even, J.; Pedesseau, L.; Kepenekian, M. Electronic surface states and dielectric selfenergy profiles in colloidal nanoscale platelets of CdSe. Physical Chemistry Chemical Physics 2014, 16, 25182.

(66) Sapori, D.; Kepenekian, M.; Pedesseau, L.; Katan, C.; Even, J. Quantum confinement and dielectric profiles of colloidal nanoplatelets of halide inorganic and hybrid organic-inorganic perovskites. Nanoscale 2016, 8, 6369.

(67) Gonze, X.; Amadon, B.; Anglade, P. M.; Beuken, J. M.; Bottin, F.; Boulanger, P.; Bruneval, F.; Caliste, D.; Caracas, R.; Côté, M.; Deutsch, T.; Genovese, L.; Ghosez, P.; Giantomassi, M.; Goedecker, S.; Hamann, D. R.; Hermet, P.; Jollet, F.; Jomard, G.; Leroux, S.; Mancini, M.; Mazevet, S.; Oliveira, M. J. T.; Onida, G.; Pouillon, Y.; Rangel, T.; Rignanese, G. M.; Sangalli, D.; Shaltaf, R.; Torrent, M.; Verstraete, M. J.; Zerah, G.; Zwanziger, J. W. ABINIT: First-principles approach to material and nanosystem properties. Computer Physics Communications 2009, 180, 2582. 
(68) Goedecker, S.; Teter, M.; Hutter, J. Separable dual-space Gaussian pseudopotentials. Physical Review B 1996, 54, 1703.

(69) Hartwigsen, C.; Goedecker, S.; Hutter, J. Relativistic separable dual-space Gaussian pseudopotentials from H to Rn. Physical Review B 1998, 58, 3641.

(70) Marques, M. A. L.; Oliveira, M. J. T.; Burnus, T. Libxc: A library of exchange and correlation functionals for density functional theory. Computer Physics Communications 2012, $183,2272$.

(71) Jiang, X.; Hoffman, J.; Stoumpos, C. C.; Kanatzidis, M. G.; Harel, E. Transient SubBand-Gap States at Grain Boundaries of $\mathrm{CH}_{3} \mathrm{NH}_{3} \mathrm{PbI}_{3}$ Perovskite Act as Fast Temperature Relaxation Centers. ACS Energy Letters 2019, 4, 1741.

TOC Graphic

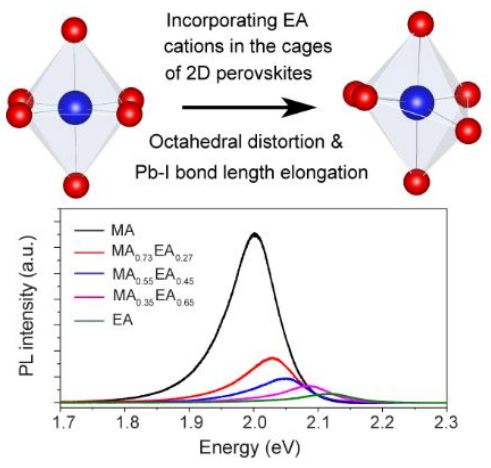

